\title{
Synthesis of a neamine dimer targeting the dimerization initiation site of HIV-1 RNA
}

\section{Anne Bodlenner, ${ }^{a}$ Aurélien Alix, ${ }^{a}$ Jean-Marc Weibel, ${ }^{a}$ Patrick Pale, ${ }^{\text {a }}$ Eric Ennifar, ${ }^{\mathrm{b}}$ Jean-Christophe Paillart, ${ }^{\mathrm{b}}$ Philippe Walter, ${ }^{\mathrm{b}}$ Roland Marquet $^{\mathrm{b}}$ and Philippe Dumas ${ }^{\mathrm{b}}$}

${ }^{a}$ Laboratoire de synthèse et réactivité organique, Institut de Chimie, Université Louis Pasteur, 4 rue Blaise Pascal, 67070 Strasbourg, France

${ }^{b}$ Architecture et réactivité de l'ARN, Université Louis Pasteur, CNRS, IBMC, 15, rue René Descartes, 67084 Strasbourg, France

ppale@chimie.u-strasbg.fr

Received Date (will be automatically inserted after manuscript is accepted)

\section{General}

${ }^{1} \mathrm{H}$ NMR (300 MHz or $500 \mathrm{MHz}$ ) and ${ }^{13} \mathrm{C}$ NMR $(75 \mathrm{MHz}$ and $125 \mathrm{MHz}$ ) were recorded on Brucker AC-300 and Brucker $\mathrm{AC}-500$. Chemical shifts were reported in units (ppm) by assigning $\mathrm{CD}_{3} \mathrm{OD}$, DMSO-d6, pyridine- $\mathrm{d} 5$ and $\mathrm{D}_{2} \mathrm{O}$ resonance in the ${ }^{1} \mathrm{H}$ spectrum respectively as $3.31 \mathrm{ppm}, 2.50 \mathrm{ppm}, 8.71 \mathrm{ppm}, 4.79 \mathrm{ppm}$ and in the ${ }^{13} \mathrm{C}$ spectrum as $49.0 \mathrm{ppm}, 39.5 \mathrm{ppm}$, $149.9 \mathrm{ppm}$. Reagents and solvents were purchased from Acros, Aldrich or Alfa-Aesar and were used without further purification. Compound 2 to $\mathbf{4}$ and compound 8c are known compounds and exhibit spectroscopic data identical to the previously reported ones in the literature. ${ }^{1}$ Nevertheless, copies of ${ }^{1} \mathrm{H}$ and ${ }^{13} \mathrm{C}$ NMR spectra are provided.

Compound 5. To a solution of $4(559 \mathrm{mg}, 0.87 \mathrm{mmol})$ and imidazole (355 $\mathrm{mg}, 5.22 \mathrm{mmol})$ in anhydrous DMF (6.1 mL) was added tertbutyldimethylsilyl chloride $(524 \mathrm{mg}, 3.48 \mathrm{mmol})$. The mixture was stirred overnight at room temperature under argon atmosphere, quenched with an aqueous solution of ammonium chloride then extracted with $\mathrm{CH}_{2} \mathrm{Cl}_{2}(3 \times 20 \mathrm{~mL})$. The organic layer was washed with brine, dried on $\mathrm{Na}_{2} \mathrm{SO}_{4}$, and concentrated in vacuo to give a syrup, which was purified

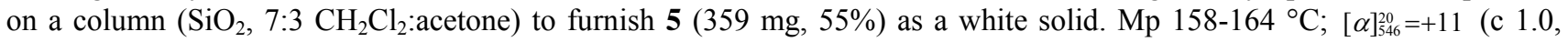
$\mathrm{MeOH})$; IR (KBr): 3100-3600(O-H; N-H v), 2930 (C-H v), 1783 (C=O v five-membered carbamate: NHCO I), 1706 (C=O v $\mathrm{Cbz}$ and six-membered carbamates: NHCO I), 1528 (N-H v and N-C=O v: NHCO II), 1458, 1404 (C-H; O-H v), 1219 , 1080; ${ }^{1} \mathrm{H}$ NMR (500 MHz, CD $\left.\mathrm{OD}\right) \delta: 0.13$ (s, 3H, $\mathrm{CH}_{3}$ TBS), 0.20 (s, 3H, $\mathrm{CH}_{3}$ TBS), 0.87 (s, 9H, tBu TBS), 1.56 (ddd,

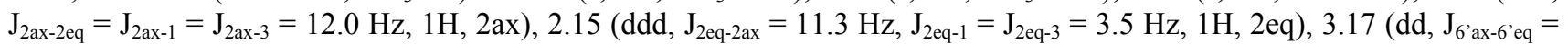
$\mathrm{J}_{6}{ }^{\prime}{ }^{\prime}-5{ }^{\prime}=10.4 \mathrm{~Hz}, 1 \mathrm{H}, 6$ 'ax), $3.45\left(\mathrm{~m}, 2 \mathrm{H}, 6\right.$ 'eq and 1), 3.57 (dd, $\left.\mathrm{J}_{4-5}=7.90 \mathrm{~Hz}, \mathrm{~J}_{4-3}=9.9 \mathrm{~Hz}, 1 \mathrm{H}, 4\right), 3.72$ (m, $2 \mathrm{H}, 6$ et 3 ), $3.76\left(\mathrm{dd}, \mathrm{J}_{2^{\prime}-3^{\prime}}=9.7 \mathrm{~Hz}, \mathrm{~J}_{2^{\prime}-1}\right.$, = $\left.3.6 \mathrm{~Hz}, 1 \mathrm{H}, 2^{\prime}\right), 3.86\left(\mathrm{dd}, \mathrm{J}_{3^{\prime}-2}{ }^{\prime}=\mathrm{J}_{3^{\prime}-4^{\prime}}=8.5 \mathrm{~Hz}, 1 \mathrm{H}, 3^{\prime}\right), 3.91\left(\mathrm{dd}, \mathrm{J}_{4^{\prime}-3^{\prime}}=\mathrm{J}_{4^{\prime}-5}{ }^{\prime}=8.5 \mathrm{~Hz}, 1 \mathrm{H}\right.$, $\left.4^{\prime}\right), 4.02\left(\mathrm{ddd}, \mathrm{J}_{5^{\prime}-4^{\prime}}=\mathrm{J}_{5^{\prime}-6^{\prime} \mathrm{ax}}=9.9 \mathrm{~Hz} . \mathrm{J}_{5^{\prime}-6^{\prime} \mathrm{eq}}=5.9 \mathrm{~Hz}, 1 \mathrm{H}, 5^{\prime}\right), 4.06\left(\mathrm{dd}, \mathrm{J}_{5-6}=10.3 \mathrm{~Hz}, \mathrm{~J}_{5-4}=7.9 \mathrm{~Hz}, 1 \mathrm{H}, 5\right), 4.82(\mathrm{~d}, \mathrm{~J}=$ $\left.12.3 \mathrm{~Hz}, 1 \mathrm{H}, \mathrm{CH}_{2} \mathrm{Ar}\right), 5.03\left(\mathrm{~d}, \mathrm{~J}=12.2 \mathrm{~Hz}, 1 \mathrm{H}, \mathrm{CH}_{2} \mathrm{Ar}\right), 5.10\left(\mathrm{~d}, \mathrm{~J}=12.2 \mathrm{~Hz}, 1 \mathrm{H}, \mathrm{CH}_{2} \mathrm{Ar}\right), 5.32\left(\mathrm{~d}, \mathrm{~J}=12.2 \mathrm{~Hz}, 1 \mathrm{H}, \mathrm{CH}_{2}\right.$ $\mathrm{Ar}), 5.57\left(\mathrm{~d}, \mathrm{~J}_{1^{\prime}-2}{ }^{\prime}=3.6 \mathrm{~Hz}, 1 \mathrm{H}, 1^{\prime}\right), 7.28-7.42(\mathrm{~m}, 10 \mathrm{H}, \mathrm{Ar}) ;{ }^{13} \mathrm{C}$ NMR $\left(125 \mathrm{MHz}, \mathrm{CD}_{3} \mathrm{OD}\right) \delta:-4.6\left(\mathrm{CH}_{3} \mathrm{TBS}\right),-3.8\left(\mathrm{CH}_{3}\right.$

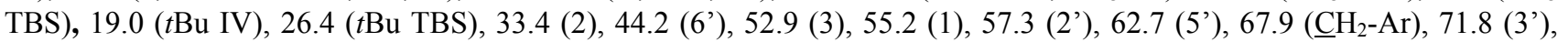
74.7 (5), 81.0 (4'), 83.2 (4), 85.6 (6), 100.4 (1'), 129.0 (Ar C $\left.C^{\mathrm{III}}\right), 129.1$ (Ar C $\left.\mathrm{C}^{\mathrm{III}}\right), 129.3$ (Ar C $\left.\mathrm{C}^{\mathrm{III}}\right), 129.5$ (Ar C $\left.\mathrm{C}^{\mathrm{III}}\right), 129.5$ (Ar

${ }^{1}$ For compound 2 and 3 see: Park, W. K. C.; Auer, M.; Jaksche, H.; Wong, C-H. J. Am. Chem. Soc. 1996, 118, 10150-10155; for compound 4 see: Kumar, V.; Remers, W. A. J. Org. Chem. 1978; for compound 8c see:, 43, 3327-31; Pavlova, A.;. Rogozhin, D. Izv. Akad. Nauk. SSSR, Ser. Khim. 1980, 5, $1078-81$. 
$\left.\mathrm{C}^{\mathrm{III}}\right), 138.0\left(\mathrm{Ar}^{\mathrm{IV}}\right), 138.0\left(\mathrm{Ar} \mathrm{C}^{\mathrm{IV}}\right), 155.4(\mathrm{C}=\mathrm{O}$ six-membered carbamate), $158.4(\mathrm{C}=\mathrm{O} \mathrm{Cbz}), 158.7(\mathrm{C}=\mathrm{O} \mathrm{Cbz}), 163.0$ $\left(\mathrm{C}=\mathrm{O}\right.$ five-membered carbamate); HRMS ES+Calculated for $\mathrm{C}_{36} \mathrm{H}_{48} \mathrm{~N}_{4} \mathrm{NaO}_{12} \mathrm{Si}\left[\mathrm{M}+\mathrm{Na}^{+}\right]$779.2930, found 779.2950.

Compound 6. To a solution of $5(660 \mathrm{mg}, 0.87 \mathrm{mmol})$ in a mixture of dioxane $(33 \mathrm{~mL})$ and water $(17.4 \mathrm{~mL})$ was added barium hydroxide $\left(275 \mathrm{mg}, 0.87 \mathrm{mmol}\right.$ ). The mixture was stirred at $50{ }^{\circ} \mathrm{C}$ for $5.5 \mathrm{~h}$, cooled, neutralized with $\mathrm{CO}_{2}$, and concentrated under reduced pressure. Water was removed by azeotropic evaporation with toluene. A chloroform extract of the residue was filtered through a pad of celite, concentrated, and purified on a column $\left(\mathrm{SiO}_{2}, 8: 2\right.$ then 7:3 $\mathrm{CH}_{2} \mathrm{Cl}_{2}$ :acetone) to furnish 6 (458 mg, $72 \%$ ) as a white solid. Mp $153-155^{\circ} \mathrm{C} ;[\alpha]_{546}^{20}=+5$ (c 1.0, MeOH); IR (KBr): 3100-3600 (O-H; N-H v), $2928(\mathrm{C}-\mathrm{H} v), 1720(\mathrm{C}=\mathrm{O} v$ six-membered carbamate: $\mathrm{NHCO}$ I), $1698(\mathrm{C}=\mathrm{O} \vee \mathrm{Cbz}$ : NHCO I), $1525(\mathrm{~N}-\mathrm{H} v$ and $\mathrm{N}-\mathrm{C}=\mathrm{O} v$ : NHCO II), 1455, 1408 (C-H; O-H v), 1260, 1042; ${ }^{1} \mathrm{H}$ NMR (500 MHz, CD 3 OD) $\delta: 0.13$ (s, 3H, $\mathrm{CH}_{3} \mathrm{TBS}$ ), 0.20 (s, $3 \mathrm{H}, \mathrm{CH}_{3}$ TBS), 0.88 (s, $9 \mathrm{H}, t \mathrm{Bu}$ TBS), 1.34 (ddd, $\left.\mathrm{J}_{2 \mathrm{ax}-2 \mathrm{eq}}=\mathrm{J}_{2 \mathrm{ax}-1}=\mathrm{J}_{2 \mathrm{ax}-3}=12.5 \mathrm{~Hz}, 1 \mathrm{H}, 2 \mathrm{ax}\right), 1.94$ (ddd, $\mathrm{J}_{2 \mathrm{eq}-2 \mathrm{ax}}=13 \mathrm{~Hz} \mathrm{~J}_{2 \mathrm{eq}-1}=\mathrm{J}_{2 \mathrm{eq}-3}=4$ $\mathrm{Hz}, 1 \mathrm{H}, 2 \mathrm{eq}), 2.67$ (ddd, $\left.\mathrm{J}_{1-6}=\mathrm{J}_{1-2 \mathrm{ax}}=9.5 \mathrm{~Hz} \mathrm{~J}_{1-2 \mathrm{eq}}=4.0 \mathrm{~Hz}, 1 \mathrm{H}, 1\right), 2.93\left(\mathrm{dd}, \mathrm{J}_{6-1}=\mathrm{J}_{6-5}=9.5 \mathrm{~Hz}, 1 \mathrm{H}, 6\right), 3.15$ (dd, $\mathrm{J}_{6^{\prime} \mathrm{ax}-6^{\prime} \mathrm{eq}}=$ $\mathrm{J}_{6}{ }^{\prime}$ ax-5 $=10.5 \mathrm{~Hz}, 1 \mathrm{H}, 6$ 'ax), $3.43\left(\mathrm{dd}, \mathrm{J}_{4-5}=\mathrm{J}_{4-3}=9.0 \mathrm{~Hz}, 1 \mathrm{H}, 4\right), 3.47\left(\mathrm{~m}, 2 \mathrm{H}, 6\right.$ 'eq et 5), $3.61(\mathrm{~m}, 1 \mathrm{H}, 3), 3.80\left(\mathrm{~m}, 1 \mathrm{H}, 2^{\prime}\right)$, $3.88\left(\mathrm{~m}, 2 \mathrm{H}, 3^{\prime}\right.$ and $\left.4^{\prime}\right), 4.06\left(\mathrm{~m}, 1 \mathrm{H}, 5^{\prime}\right), 4.84\left(\mathrm{~d}, \mathrm{~J}=15.0 \mathrm{~Hz}, 1 \mathrm{H}, \mathrm{C}_{2} \mathrm{Ar}\right), 5.02\left(\mathrm{~d}, \mathrm{~J}=10.0 \mathrm{~Hz}, 1 \mathrm{H}, \mathrm{C}_{2} \mathrm{Ar}\right), 5.10(\mathrm{~d}, \mathrm{~J}=$ $\left.10.0 \mathrm{~Hz}, 1 \mathrm{H}, \mathrm{CH}_{2} \mathrm{Ar}\right), 5.31\left(\mathrm{~d}, \mathrm{~J}=15.0 \mathrm{~Hz}, 1 \mathrm{H}, \mathrm{CH}_{2} \mathrm{Ar}\right), 5.57\left(\mathrm{~d}, \mathrm{~J}_{1^{\prime}-2}{ }^{\prime}=3.8 \mathrm{~Hz}, 1 \mathrm{H}, 1\right.$ '), 7.25-7.41 (m, 10H, Ar); ${ }^{13} \mathrm{C} \mathrm{NMR}$ (125 MHz, $\left.\mathrm{CD}_{3} \mathrm{OD}\right)$ ) : -4.6 ( $\left.\mathrm{CH}_{3} \mathrm{TBS}\right),-3.8\left(\mathrm{CH}_{3} \mathrm{TBS}\right), 19.0$ ( $\left.t \mathrm{Bu} \mathrm{IV}\right), 26.4$ (Me $\left.t \mathrm{Bu}\right), 36.0$ (2), 44.2 (6'), 51.5 (3), 52.1 (1), 57.3 (2') , 62.6 (5'), $67.7\left(\mathrm{CH}_{2}-\mathrm{Ar}\right), 67.8\left(\mathrm{CH}_{2}-\mathrm{Ar}\right), 71.9$ (3'), 78.3 (5), 79.0 (6), 81.1 (4'), 82.1 (4), 100.2 (1'), 129.0 (Ar $\left.\mathrm{C}^{\mathrm{III}}\right), 129.2\left(\mathrm{Ar} \mathrm{C}^{\mathrm{III}}\right), 129.5\left(\mathrm{Ar} \mathrm{C}^{\mathrm{III}}\right), 129.5\left(\mathrm{Ar} \mathrm{C}^{\mathrm{III}}\right), 138.0\left(\mathrm{Ar} \mathrm{C}^{\mathrm{IV}}\right), 138.1\left(\mathrm{Ar} \mathrm{C}^{\mathrm{IV}}\right), 155.5(\mathrm{C}=\mathrm{O}$ six-membered carbamate), $158.5(\mathrm{C}=\mathrm{O} \mathrm{Cbz})$; HRMS ES+ Calculated for $\mathrm{C}_{35} \mathrm{H}_{51} \mathrm{~N}_{4} \mathrm{O}_{11} \mathrm{Si}\left[\mathrm{M}+\mathrm{H}^{+}\right]$731.3318, found 731.3316.

Compound 9c. To an ice cold suspension of N-hydroxysuccinimide (1g, $8.69 \mathrm{mmol})$ and fumaric acid $(504 \mathrm{mg}, 4.34$ mmol) in freshly distilled pyridine $(1.43 \mathrm{~mL}, 17.38 \mathrm{mmol})$ and chlorobenzene $(5.4 \mathrm{~mL})$, trifluoroacetic anhydride $(1.23 \mathrm{~mL}$, $8.69 \mathrm{mmol}$ ) was added dropwise with stirring under argon atmosphere. After $10 \mathrm{~min}$ at $0^{\circ} \mathrm{C}$, the mixture was stirred $2 \mathrm{~h}$ at room temperature and was kept overnight at $4{ }^{\circ} \mathrm{C}$. The solid was filtered and washed thoroughly with ethanol. Recrystallisation from acetonitrile furnished a brown product $(889 \mathrm{mg}, 66 \%) .{ }^{1} \mathrm{H}$ NMR $(300 \mathrm{MHz}, \mathrm{DMSO}) \delta 2.87(\mathrm{~s}, 4 \mathrm{H}$, $\left.\mathrm{CH}_{2}\right), 7.48(\mathrm{~s}, 1 \mathrm{H}, \mathrm{CH}) ;{ }^{13} \mathrm{C}$ NMR $(75 \mathrm{MHz}, \mathrm{DMSO}) \delta 26.0\left(\mathrm{CH}_{2}\right), 132.3(\mathrm{CH}=\mathrm{CH}), 160.4(\mathrm{O}-\underline{\mathrm{CO}}-\mathrm{CH}=), 170.3\left(\mathrm{CH}_{2}-\underline{\mathrm{CO}}-\right.$ $\mathrm{N})$; HRMS ES+ Calculated for $\mathrm{C}_{74} \mathrm{H}_{101} \mathrm{~N}_{8} \mathrm{NaO}_{24} \mathrm{Si}_{2}\left[\mathrm{M}+\mathrm{Na}^{+}\right]$333.0329, found 333.0319.

Compound 11. Using the one-pot peptide coupling method. To a solution of 6 (500 $\mathrm{mg}, 0.68 \mathrm{mmol})$ and $8 \mathrm{a}(38 \mathrm{mg}, 0.32$ $\mathrm{mmol})$ in acétonitrile $(10 \mathrm{~mL})$ under argon atmosphere was added diisopropylcarbodiimide $(106 \mu \mathrm{L}, 0.68 \mathrm{mmol})$ and HOBt $(92 \mathrm{mg}, 0.68 \mathrm{mmol})$. The reaction mixture was stirred $72 \mathrm{~h}$ at room temperature, concentrated under reduced pressure. The resulting solid was purified on a column $\left(\mathrm{SiO}_{2}, 9: 1\right.$ then $8: 2$ then 6:4 $\left.\mathrm{CH}_{2} \mathrm{Cl}_{2}: \mathrm{MeOH}\right)$ to furnish a white solid (375 $\left.\mathrm{mg}, 71 \%\right)$. $\mathrm{Mp} 236-244{ }^{\circ} \mathrm{C}(\mathrm{dec})$; IR $(\mathrm{KBr}): 3100-3600(\mathrm{O}-\mathrm{H} ; \mathrm{N}-\mathrm{H}$ v), $2950(\mathrm{C}-\mathrm{H}$ v), $1701(\mathrm{C}=\mathrm{O} v$ (six-membered carbamate) and $\mathrm{C}=\mathrm{O} v(\mathrm{Cbz})$ : NHCO I), $1650(\mathrm{C}=\mathrm{O} v$ : $\mathrm{NHCO}$ I and $\mathrm{C}=\mathrm{C} v), 1522(\mathrm{~N}-\mathrm{H} v$ and $\mathrm{N}-\mathrm{C}=\mathrm{O} v$ : NHCO II), 1457, $1405(\mathrm{C}-\mathrm{H}$; O-H v), 1260; ${ }^{1} \mathrm{H}$ NMR (300 MHz, MeOD) $\delta: 0.12$ (s, 3H, $\mathrm{CH}_{3}$ TBS), 0.20 (s, 3H, $\mathrm{CH}_{3} \mathrm{TBS}$ ), 0.87 (s, 9H, tBu TBS), 1.86 (ddd, $\left.1 \mathrm{H}, \mathrm{J}_{2 \mathrm{ax}-2 \mathrm{eq}}=\mathrm{J}_{2 \mathrm{ax}-1}=\mathrm{J}_{2 \mathrm{ax}-3}=12.4 \mathrm{~Hz}, 2 \mathrm{ax}\right), 1.97\left(\mathrm{ddd}, \mathrm{J}_{2 \mathrm{eq}-2 \mathrm{ax}}=12.4 \mathrm{~Hz} \mathrm{~J}_{2 \mathrm{eq}-1}=\mathrm{J}_{2 \mathrm{eq}-3}=4.2 \mathrm{~Hz}, 1 \mathrm{H}, 2 \mathrm{eq}\right), 2.47\left(\mathrm{~s}, 2 \mathrm{H}, \mathrm{CH}_{2}\right.$ spacer), $3.13\left(\mathrm{dd}, 1 \mathrm{H}, \mathrm{J}_{6^{\prime} \text { 'ax-6'eq }}=\mathrm{J}_{6^{\prime} \text { 'ax-5 }}=10.3 \mathrm{~Hz}, 6^{\prime}\right.$ 'ax), $3.21\left(\mathrm{dd}, 1 \mathrm{H}, \mathrm{J}_{4-5}=\mathrm{J}_{4-3}=9.9 \mathrm{~Hz}, 4\right), 3.47\left(\mathrm{~m}, 2 \mathrm{H}, 6\right.$ and $6^{\prime}{ }_{\text {éq }}$ ), 3.63 (m, $2 \mathrm{H}, 5$ and 1), $3.76\left(\mathrm{~m}, 2 \mathrm{H}, 2^{\prime}\right.$ and 3), $3.90\left(\mathrm{~m}, 2 \mathrm{H}, 3^{\prime}\right.$ and $\left.4^{\prime}\right), 4.05\left(\mathrm{~m}, 1 \mathrm{H}, 5^{\prime}\right), 5.05\left(\mathrm{~d}, 2 \mathrm{H}, \mathrm{J}=12.4 \mathrm{~Hz}, \mathrm{CH}_{2}-\mathrm{Ar}\right.$ on $\left.\mathrm{N} 2^{\prime}\right), 5.29\left(\mathrm{~d}, 1 \mathrm{H}, \mathrm{J}=12.5 \mathrm{~Hz}, \mathrm{CH}_{2}-\mathrm{Ar}\right.$ on $\left.\mathrm{N} 3\right), 5.46\left(\mathrm{~d}, 1 \mathrm{H}, \mathrm{J}_{1^{\prime}-2}=3.3 \mathrm{~Hz}, 1^{\prime}\right), 7.34(\mathrm{~m}, 10 \mathrm{H}, \mathrm{Ar}) ;{ }^{13} \mathrm{C} \mathrm{NMR}(75 \mathrm{MHz}$, MeOD) $\delta$ : -4.6 ( $\left.\mathrm{CH}_{3} \mathrm{TBS}\right),-3.8$ ( $\left.\mathrm{CH}_{3} \mathrm{TBS}\right), 19.0$ ( $t \mathrm{Bu}$ IV), 26.4 (Me $\left.t \mathrm{Bu}\right), 32.4\left(\mathrm{CH}_{2}\right.$ spacer), 37.0 (2), 44.2 (6'), 51.2 (1); 51.5 (3), $57.4\left(2^{\prime}\right), 62.6\left(5^{\prime}\right), 67.7\left(\mathrm{CH}_{2}-\mathrm{Ar}\right.$ on N3), $67.8\left(\mathrm{CH}_{2}-\mathrm{Ar}\right.$ on N2'), 71.9 (3'), 76.5 (6), 78.5 (5), 81.1 (4'), 81.9 (4), $100.3\left(1^{\prime}\right), 129.0\left(\mathrm{Ar} \mathrm{C}^{\mathrm{III}}\right), 129.2\left(\mathrm{Ar} \mathrm{C} \mathrm{ClI}^{\mathrm{III}}\right), 129.4\left(\mathrm{Ar} \mathrm{C}^{\mathrm{III}}\right), 129.5$ ( $\left.\mathrm{Ar} \mathrm{C}^{\mathrm{III}}\right), 138.0\left(\mathrm{Ar} \mathrm{C}^{\mathrm{IV}}\right.$ on N2'), 138.1 (Ar $\mathrm{C}^{\mathrm{IV}}$ on N3), $155.5(\mathrm{C}=\mathrm{O}$ six-membered carbamate $), 158.4(\mathrm{C}=\mathrm{O} \mathrm{Cbz}), 158.7(\mathrm{C}=\mathrm{O} \mathrm{Cbz}), 174.9(\mathrm{C}=\mathrm{O}$ spacer $)$; HRMS ES+Calculated for $\mathrm{C}_{74} \mathrm{H}_{101} \mathrm{~N}_{8} \mathrm{O}_{24} \mathrm{Si}_{2}\left[\mathrm{M}+\mathrm{Na}^{+}\right]$1565.6438, found 1565.6149 .

Compound 12. Using the bis(pivaloyl)anhydride method. To a solution of fumaric acid (15.9 $\mathrm{mg}, 0.137 \mathrm{mmol})$ and diisopropylethylamine $(59 \mu \mathrm{L}, 0.342 \mathrm{mmol})$ at $0{ }^{\circ} \mathrm{C}$ in dichloromethane $(1.8 \mathrm{~mL})$ under argon atmosphere, pivaloyl chloride $\left(37 \mu \mathrm{L}, 0.300 \mathrm{mmol}\right.$ ) was added drowpwise with stirring. After $10 \mathrm{~min}$ at $0{ }^{\circ} \mathrm{C}$ and $1 \mathrm{~h}$ at room temperature, the reaction mixture was added dropwise to a solution of $6(200 \mathrm{mg}, 0.273 \mathrm{mmol})$ and diisopropylethylamine $(118 \mu \mathrm{L}, 0.684 \mathrm{mmol})$ in dichloromethane $(6 \mathrm{~mL})$ at $0{ }^{\circ} \mathrm{C}$. The reaction mixture was stirred $1 \mathrm{~h}$ at $0{ }^{\circ} \mathrm{C}$ and $3 \mathrm{~h} 15$ at roomm temperature, quenched with acetone and concentrated under reduced presure to give a solid, which was purified on a column $\left(\mathrm{SiO}_{2}, 9: 1\right.$ then 8:2 $\mathrm{CH}_{2} \mathrm{Cl}_{2}: \mathrm{MeOH}$ ) to furnish a white solid (144 mg, $68 \%$ ).

Using the bis(succinimidyl)diester method. A solution of $6(2.452 \mathrm{~g}, 3.35 \mathrm{mmol})$ and 9c $(486 \mathrm{mg}, 1.52 \mathrm{mmol})$ in anhydrous DMF $(23 \mathrm{~mL})$ under argon atmosphere was stirred for $3 \mathrm{~h} 20$ at room temperature. The reaction mixture was concentrated and treated with ice cold water. The resulting white solid was filtered and washed with water, then purified on a column $\left(\mathrm{SiO}_{2}, 9: 1\right.$ then $\left.6: 4 \mathrm{CH}_{2} \mathrm{Cl}_{2}: \mathrm{MeOH}\right)$ to furnish a white solid $(2.147 \mathrm{~g}, 92 \%)$. Mp $240{ }^{\circ} \mathrm{C}(\mathrm{dec}) ;[\alpha]_{546}^{20}=+3$ (c 1.1 , 
pyridine); IR (KBr): 3100-3600 (O-H; N-H v), $2950(\mathrm{C}-\mathrm{H}$ v), $1701(\mathrm{C}=\mathrm{O}$ v six-membered carbamate and $\mathrm{C}=\mathrm{O} v \mathrm{Cbz}$ : NHCO I), $1650\left(\mathrm{C}=\mathrm{O}\right.$ v: NHCO I and $\mathrm{C}=\mathrm{C}$ v), $1522\left(\mathrm{~N}-\mathrm{H} v\right.$ and $\mathrm{N}-\mathrm{C}=\mathrm{O} v$ : NHCO II), 1457, $1405(\mathrm{C}-\mathrm{H} ; \mathrm{O}-\mathrm{H} v), 1259 ;{ }^{1} \mathrm{H}$ NMR (500 MHz, pyridine-d5) $\delta: 0.29$ (s, 3H, $\mathrm{CH}_{3}$ TBS), 0.48 (s, 3H, $\mathrm{CH}_{3}$ TBS), 1.05 (s, 9H, $t \mathrm{Bu}$ TBS), 1.86 (ddd, $1 \mathrm{H}, \mathrm{J}_{2 \mathrm{ax}-}$

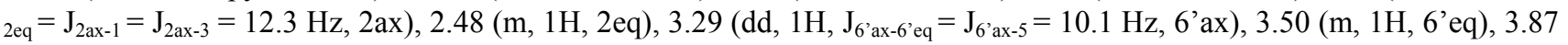
(m, 2H, 5 and 6), $4.08(\mathrm{~m}, 1 \mathrm{H}, 4), 4.15\left(\mathrm{dd}, 1 \mathrm{H}, \mathrm{J}_{4^{\prime}-5}{ }^{\prime}=\mathrm{J}_{4^{\prime}-{ }^{\prime}}\right.$, $\left.=8.7 \mathrm{~Hz}, 4^{\prime}\right), 4.26(\mathrm{~m}, 1 \mathrm{H}, 3), 4.40(\mathrm{~m}, 1 \mathrm{H}, 1), 4.52$ (m, 2H, ${ }^{\prime}$

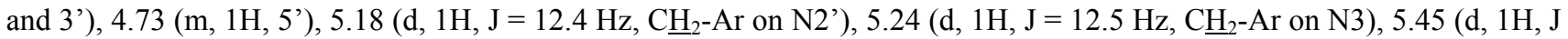
$=12.3 \mathrm{~Hz}, \mathrm{CH}_{2}-\mathrm{Ar}$ on N2'), $5.75\left(\mathrm{~d}, 1 \mathrm{H}, \mathrm{J}=12.7 \mathrm{~Hz}, \mathrm{CH}_{2}-\mathrm{Ar}\right.$ on N3), 6.20 (s, 1H, 1'), 7.21 (d, 1H, OH on 6), 7.33 (m, $5 \mathrm{H}$, $\mathrm{Ar}), 7.50(\mathrm{~m}, 5 \mathrm{H}, \mathrm{Ar}), 7.56(\mathrm{~s}, 1 \mathrm{H}, \mathrm{CH}=\mathrm{CH}), 7.67$ (bs, $1 \mathrm{H}, \mathrm{OH}$ on 5), $8.29\left(\mathrm{~d}, 1 \mathrm{H}, \mathrm{J}_{\mathrm{NH}-6^{\prime}}=4.4 \mathrm{~Hz}, \mathrm{NH}\right.$ on $\left.6^{\prime}\right), 8.52(\mathrm{~d}, 1 \mathrm{H}$, $\mathrm{J}_{\mathrm{NH}-3}=9.1 \mathrm{~Hz}, \mathrm{NH}$ on 3$), 8.64\left(\mathrm{~d}, 1 \mathrm{H}, \mathrm{J}_{\mathrm{NH}-2},=8.5 \mathrm{~Hz}, \mathrm{NH}\right.$ on 2 '), $9.38\left(\mathrm{~d}, 1 \mathrm{H}, \mathrm{J}_{\mathrm{NH}-1}=7.8 \mathrm{~Hz}, \mathrm{NH}\right.$ on 1$) ;{ }^{13} \mathrm{C} \mathrm{NMR}(125$ $\mathrm{MHz}$, pyridine-d5) $\delta$ : -4.7 ( $\left.\mathrm{CH}_{3} \mathrm{TBS}\right)$, -3. 6( $\left.\mathrm{CH}_{3} \mathrm{TBS}\right), 18.6$ ( $\left.t \mathrm{Bu} \mathrm{IV}\right), 26.2$ (Me $\left.t \mathrm{Bu}\right), 35.8$ (2), 44.0 (6'), 51.0 (1 and 3), 57.1 (2'), 62.5 (5'), 66.5 ( $\underline{\mathrm{CH}}_{2}$-Ar en N3), $66.7\left(\underline{\mathrm{CH}}_{2}-\mathrm{Ar}\right.$ en N2'), 71.8 (3'), 76.6 (6), 78.4 (5), 80.2 (4'), 82.3 (4), 100.5 (1'), 128.1

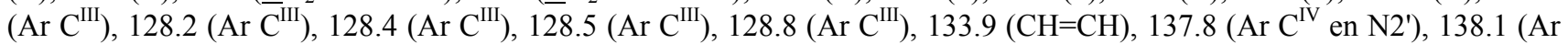
$\mathrm{C}^{\mathrm{IV}}$ en N3), $153.3(\mathrm{C}=\mathrm{O}$ six-membered carbamate), $156.9(\mathrm{C}=\mathrm{O} \mathrm{Cbz}), 157.6(\mathrm{C}=\mathrm{O} \mathrm{Cbz}), 165.0(\mathrm{C}=\mathrm{O}$ spacer $)$; HRMS $\mathrm{ES}+$ Calculated for $\mathrm{C}_{74} \mathrm{H}_{101} \mathrm{~N}_{8} \mathrm{O}_{24} \mathrm{Si}_{2}\left[\mathrm{M}+\mathrm{H}^{+}\right]$1541.6462, found 1541.6456.

Compound 13. Compound 11 or $12(300 \mathrm{mg}, 0.194 \mathrm{mmol})$ was dissolved in dry liquid ammonia $(\sim 40 \mathrm{~mL})$ and to this solution, small pieces of sodium metal $(210 \mathrm{mg}, 0.14 \mathrm{mmol})$ were added. The dark blue colored solution was stirred at -78 ${ }^{\circ} \mathrm{C}$ for $2 \mathrm{~h} 30$ and neutralized with acetic acid $(0.896 \mathrm{~mL}, 15.52 \mathrm{mmol})$. The clear white solution was evaporated and the residue was purified on a column $\left(\mathrm{SiO}_{2}, 5: 5: 0,5\right.$ then 3:7:0,5 dioxane:MeOH: $\left.\mathrm{NH}_{3}\right)$ to furnish a white solid $(142 \mathrm{mg}$, 73\%). $\mathrm{Mp} 175^{\circ} \mathrm{C}(\mathrm{dec})$; $[\alpha]_{546}^{20}=+8.7$ (c 0.97, MeOH); IR (KBr): 3100-3600 (O-H; N-H v), 2929 (C-H v), 1708 (C=O six-membered carbamate $v$ : NHCO I), $1650\left(\mathrm{C}=\mathrm{O} v\right.$ : NHCO I), $1522(\mathrm{~N}-\mathrm{H} v$ and $\mathrm{N}-\mathrm{C}=\mathrm{O} v$ : NHCO II $), 1462,1384,1257,1101 ;{ }^{1} \mathrm{H}$ NMR (300 MHz, CD 3 OD) $\delta: 0.20\left(\mathrm{~s}, 3 \mathrm{H}, \mathrm{CH}_{3} \mathrm{TBS}\right), 0.24\left(\mathrm{~s}, 3 \mathrm{H}, \mathrm{CH}_{3} \mathrm{TBS}\right), 0.95(\mathrm{~s}, 9 \mathrm{H}, t \mathrm{Bu}$ TBS$), 1.26\left(\mathrm{ddd}, 1 \mathrm{H}, \mathrm{J}_{2 \mathrm{ax}-2 \mathrm{eq}}=\mathrm{J}_{2 \mathrm{ax}-1}=\right.$ $\left.\mathrm{J}_{2 \mathrm{ax}-3}=12.2 \mathrm{~Hz}, 2 \mathrm{ax}\right), 2.01$ (ddd, 1H, 2eq), 2.50 (m, 2H, $\mathrm{CH}_{2}$ spacer), 2.85 (m, 2H, 2' and 3'), 3.18 (dd, 1H, 6'ax ), 3.21 (dd, $1 \mathrm{H}, 4), 3.33$ (dd, 1H, 6), 3.45 (m, 1H, 6'), 3.55 (dd, 1H, J = 7.7 Hz, J = 9.1 Hz, 5), 3.76 (m, 1H, 1), 3.82 (m, $1 \mathrm{H}, 4$ '), 3.86 $\left(\mathrm{m}, 1 \mathrm{H}, 3^{\prime}\right), 4.20\left(\mathrm{~m}, 1 \mathrm{H}, 5^{\prime}\right), 5.29\left(\mathrm{~d}, 1 \mathrm{H}, \mathrm{J}_{1^{\prime}-2}=3.8 \mathrm{~Hz}, 1^{\prime}\right) ;{ }^{13} \mathrm{C}$ NMR $\left(75 \mathrm{MHz}, \mathrm{CD}_{3} \mathrm{OD}\right) \delta:-4.5\left(\mathrm{CH}_{3} \mathrm{TBS}^{\prime}\right),-3.7\left(\mathrm{CH}_{3}\right.$ TBS), 19.2 ( $t \mathrm{Bu}$ IV), $26.5\left(\mathrm{CH}_{3} \mathrm{tBu}\right), 32.6\left(\mathrm{CH}_{2}\right.$ spacer), 36.2 (2), 44.2 (6’), 50.9 (3), 51.3 (1), 57.8 (2'), 63.1 (5’), 74.6 (3’'), 76.1 (6), 77.7 (5), 80.6 (4'), 89.6 (4), 103.1 (1'), 155.5 (C=O six-membered carbamate), 174.8 (C=O spacer); HRMS $\mathrm{ES}+$ Calculated for $\mathrm{C}_{42} \mathrm{H}_{79} \mathrm{~N}_{8} \mathrm{O}_{16} \mathrm{Si}_{2}\left[\mathrm{M}+\mathrm{H}^{+}\right]$1007.5147, found 1007.5151.

Compound 14. A solution of compound $13(172 \mathrm{mg}, 0.17 \mathrm{mmol})$ in methanol $(0.5 \mathrm{~mL})$, was treated with $2 \mathrm{~mL}$ of $1 \mathrm{M}$ hydrochloric acid, stirred for $10 \mathrm{~min}$ and evaporated under reduced pressure to conduce to a white solid (157 mg, quantitative). $\mathrm{Mp} 168{ }^{\circ} \mathrm{C}(\mathrm{dec}) ;[\alpha]_{589}^{20}+15\left(\mathrm{c}=1.0 ; \mathrm{H}_{2} \mathrm{O}\right)$; IR $(\mathrm{KBr}): 3240-3700(\mathrm{O}-\mathrm{H} ; \mathrm{N}-\mathrm{H} v), 2500-3240\left(\mathrm{NH}_{2} v\right), 1700$ $(\mathrm{C}=\mathrm{O}$ six-membered carbamate $v$ : NHCO I), $1636(\mathrm{C}=\mathrm{O} v$ : NHCO I), $1560(\mathrm{~N}-\mathrm{H} v$ and $\mathrm{N}-\mathrm{C}=\mathrm{O} v$ : NHCO II), $1408(\mathrm{C}-\mathrm{H} v$ and $\mathrm{O}-\mathrm{H} v), 1113(\mathrm{C}-\mathrm{O} v$ and $\mathrm{C}-\mathrm{N} v) ;{ }^{1} \mathrm{H}$ NMR $\left(500 \mathrm{MHz}, \mathrm{D}_{2} \mathrm{O}\right): 1.72\left(\mathrm{ddd}, 1 \mathrm{H}, \mathrm{J}_{2 \mathrm{ax}-2 \mathrm{éq}}=\mathrm{J}_{2 \mathrm{ax}-1}=\mathrm{J}_{2 \mathrm{ax}-3}=12.6 \mathrm{~Hz}, 2 \mathrm{ax}\right), 2.30$

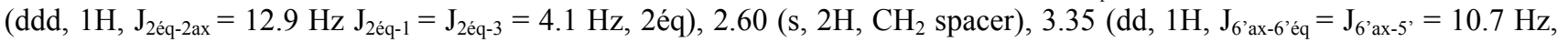
6'ax), $3.53\left(\mathrm{dd}, 1 \mathrm{H}, \mathrm{J}_{3-4}=\mathrm{J}_{3-2}=9.6 \mathrm{~Hz}, 3\right), 3.53\left(\mathrm{dd}, 1 \mathrm{H}, \mathrm{J}_{6-5}=\mathrm{J}_{6-1}=10.1 \mathrm{~Hz}, 6\right), 3.58\left(\mathrm{dd}, 1 \mathrm{H}, \mathrm{J}_{2^{\prime}-3^{\prime}},=10.7 \mathrm{~Hz} . \mathrm{J}_{2^{\prime}-1}\right.$, $=3.8$ $\mathrm{Hz}, 2^{\prime}$ ), 3.65 (dd, $1 \mathrm{H}, \mathrm{J}_{6}$ 'éq-6'ax $=10.7 \mathrm{~Hz}$. $\mathrm{J}_{6}$ 'éq-5 $=5.7 \mathrm{~Hz}, 6$ 'éq), 3.71 (dd, $\left.1 \mathrm{H}, \mathrm{J}_{5-4}=\mathrm{J}_{5-6}=9.3 \mathrm{~Hz}, 5\right), 3.88$ (ddd, $1 \mathrm{H}, \mathrm{J}_{1-2 \mathrm{ax}}=$ $\left.\mathrm{J}_{1-6}=10.4 \mathrm{~Hz} . \mathrm{J}_{1-2 e ́ q}=4.3 \mathrm{~Hz}, 1\right), 3.93\left(\mathrm{dd}, 1 \mathrm{H}, \mathrm{J}_{4-3}=\mathrm{J}_{4-5}=9.6 \mathrm{~Hz}, 4\right), 4.20\left(\mathrm{dd}, 1 \mathrm{H}, \mathrm{J}_{4^{\prime}-3^{\prime}}=\mathrm{J}_{4^{\prime}-5}{ }^{\prime}=9.3 \mathrm{~Hz}, 4^{\prime}\right), 4.27(\mathrm{dd}, 1 \mathrm{H}$, $\left.\mathrm{J}_{3^{\prime}-4^{\prime}}=\mathrm{J}_{3^{\prime}-2}{ }^{\prime}=9.9 \mathrm{~Hz}, 3^{\prime}\right), 4.29\left(\mathrm{~m}, 1 \mathrm{H}, 5^{\prime}\right), 5.91\left(\mathrm{~d}, 1 \mathrm{H}, \mathrm{J}_{1^{\prime}-2},=3.8 \mathrm{~Hz}, 1^{\prime}\right) ;{ }^{13} \mathrm{C} \mathrm{NMR}\left(125 \mathrm{MHz}, \mathrm{D}_{2} \mathrm{O}\right): 30.4(2), 30.9\left(\mathrm{CH}_{2}\right.$ spacer), 42.0 (6’), 48.7 (3), 48.8 (1), 53.4 (2’), 61.6 (3'), 66.3 (5'), 73.7 (6), 75.5 (5), 77.5 (4'), 79.2 (4), 96.7 (1'), 155.2 $\left(\mathrm{C}=\mathrm{O}\right.$ six-membered carbamate), $174.8(\mathrm{C}=\mathrm{O}$ spacer$)$; HRMS ES+ calculated for $\mathrm{C}_{30} \mathrm{H}_{51} \mathrm{~N}_{8} \mathrm{O}_{16}\left[\mathrm{M}+\mathrm{H}^{+}\right] 779.342$ found 779.338 .

Compound 15. Compound 14 (157 mg, $0.17 \mathrm{mmol})$ was dissolved in water (5 mL) and Amberlyst $\mathrm{A}^{26}\left(\mathrm{HO}^{-}\right)(488 \mathrm{mg})$ was added. The suspension was stirred for $20 \mathrm{~min}$ at room temperature, the resin was filtered, washed with water $(10 \mathrm{~mL})$ and dioxane $(15 \mathrm{~mL})$. Every three hours, barium hydroxide $(354 \mathrm{mg}, 1.11 \mathrm{mmol})$ and water $(12.6 \mathrm{~mL})$ were added in three egal portions to this filtrate (i.e. 3 times $118 \mathrm{mg}$ of barium hydroxide in $4.2 \mathrm{~mL}$ ). The resulting mixture was stirred at $50{ }^{\circ} \mathrm{C}$ for $9 \mathrm{~h}$, cooled and neutralised with $\mathrm{CO}_{2}$. The barium salts were filtered through a pad of celite, washed with DMF. The filtrate was concentrated and purified on a column $\left(\mathrm{SiO}_{2}\right.$, 5:5:0,5 then 2:8:1 dioxane: $\left.\mathrm{H}_{2} \mathrm{O}: \mathrm{NH}_{3}\right)$ to furnish a white solid. This solid was dissolved in $1 \mathrm{M}$ hydrochloric acid and stirred. The remaining solid was removed by filtration, and the filtrate was evaporated under reduced pressure to furnish the hexachlorohydrate salt $15(70 \mathrm{mg}, 0.11 \mathrm{mmol}, 67 \%)$ as a yellow solid. Mp $120{ }^{\circ} \mathrm{C}(\mathrm{dec}) ;[\alpha]_{546}^{20}=+59$ (c 1.0, $\left.\mathrm{H}_{2} \mathrm{O}\right)$; IR $(\mathrm{KBr}): 2900-3700\left(\mathrm{O}-\mathrm{H} ; \mathrm{N}-\mathrm{H}\right.$ v), 2600-2900 $\left(\mathrm{NH}_{2} v\right), 1651(\mathrm{C}=\mathrm{O} v: \mathrm{NHCO} \mathrm{I})$, $1504(\mathrm{~N}-\mathrm{H} v$ and N-C $=\mathrm{O} v$ : NHCO II $), 1380,1026 ;{ }^{1} \mathrm{H}$ NMR $\left(500 \mathrm{MHz}, \mathrm{D}_{2} \mathrm{O}\right) \delta: 1.71\left(\mathrm{ddd}, 1 \mathrm{H}, \mathrm{J}_{2 \mathrm{ax}-2 \mathrm{eq}}=\mathrm{J}_{2 \mathrm{ax}-1}=\mathrm{J}_{2 \mathrm{ax}-3}=12.6\right.$

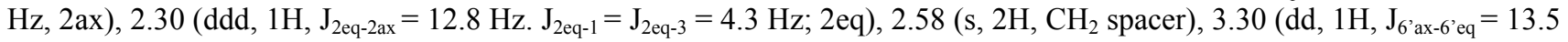

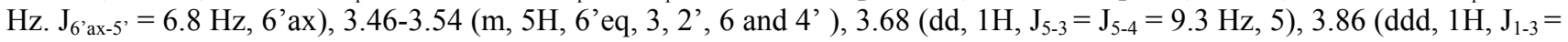
$\left.\mathrm{J}_{1-2 \mathrm{ax}}=12.1 \mathrm{~Hz} . \mathrm{J}_{1-2 \mathrm{eq}}=4.3 \mathrm{~Hz}, 1\right), 3.94\left(\mathrm{dd}, 1 \mathrm{H}, \mathrm{J}_{4-3}=\mathrm{J}_{4-5}=9.8 \mathrm{~Hz}, 4\right), 4.00\left(\mathrm{ddd}, 1 \mathrm{H}, \mathrm{J}_{3-4}=\mathrm{J}_{3-2 \mathrm{ax}}=9.1 \mathrm{~Hz} . \mathrm{J}_{3-2 \mathrm{eq}}=1.7 \mathrm{~Hz}\right.$, 3), $4.03\left(\mathrm{ddd}, 1 \mathrm{H}, \mathrm{J}_{5^{\prime}-4^{\prime}}=\mathrm{J}_{5^{\prime}-6^{\prime} \mathrm{ax}}=6.8 \mathrm{~Hz}\right.$. $\left.\mathrm{J}_{5^{\prime}-6^{\prime} \mathrm{eq}}=3.5 \mathrm{~Hz}, 5^{\prime}\right), 5.92\left(\mathrm{~d}, 1 \mathrm{H}, \mathrm{J}_{1^{\prime}-2}{ }^{\prime}=3.9 \mathrm{~Hz}, 1^{\prime}\right){ }^{\prime}{ }^{13} \mathrm{C}^{2} \mathrm{NMR}\left(125 \mathrm{MHz}, \mathrm{D}_{2} \mathrm{O}\right) \delta$ : 31.1 (2), 31.5 ( $\mathrm{CH}_{2}$ spacer), 40.9 (6’), 49.6 (3 and 1), 54.3 (2'), 69.1 (3'), 69.9 (5'), 71.4 (4'), 74.7 (6), 76.5 (5), 79.2 (4), $96.8\left(1^{\prime}\right), 175.6(\mathrm{C}=\mathrm{O})$; HRMS ES+ Calculated for $\mathrm{C}_{28} \mathrm{H}_{55} \mathrm{~N}_{8} \mathrm{O}_{14}\left[\mathrm{M}+\mathrm{H}^{+}\right]$727.3832, found 727.3837 . 
Compound 2

$$
\mathrm{D}_{2} \mathrm{O}
$$

${ }^{1} \mathrm{H}: 500 \mathrm{MHz}$

${ }^{13} \mathrm{C}: 125 \mathrm{MHz}$
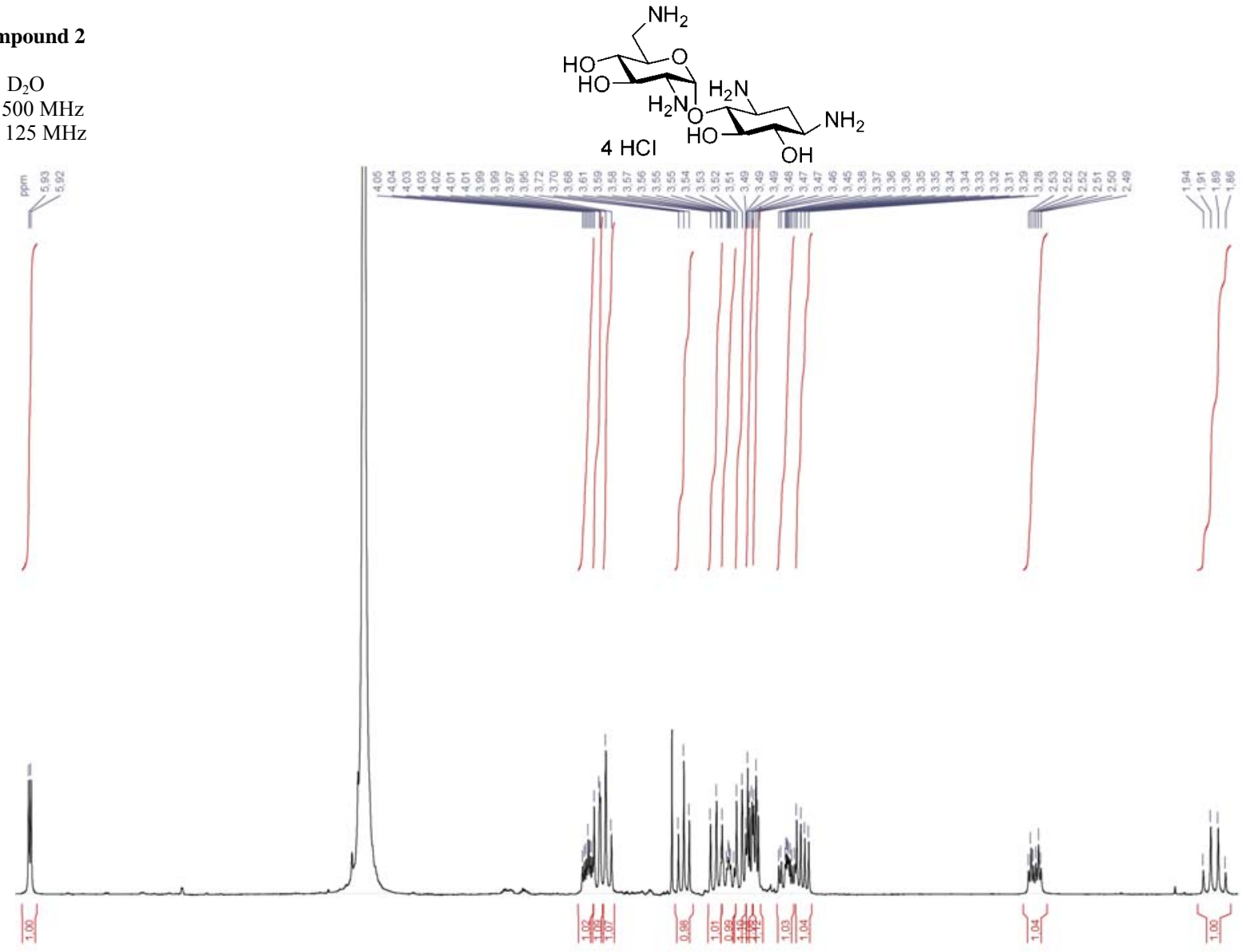

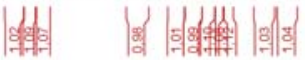
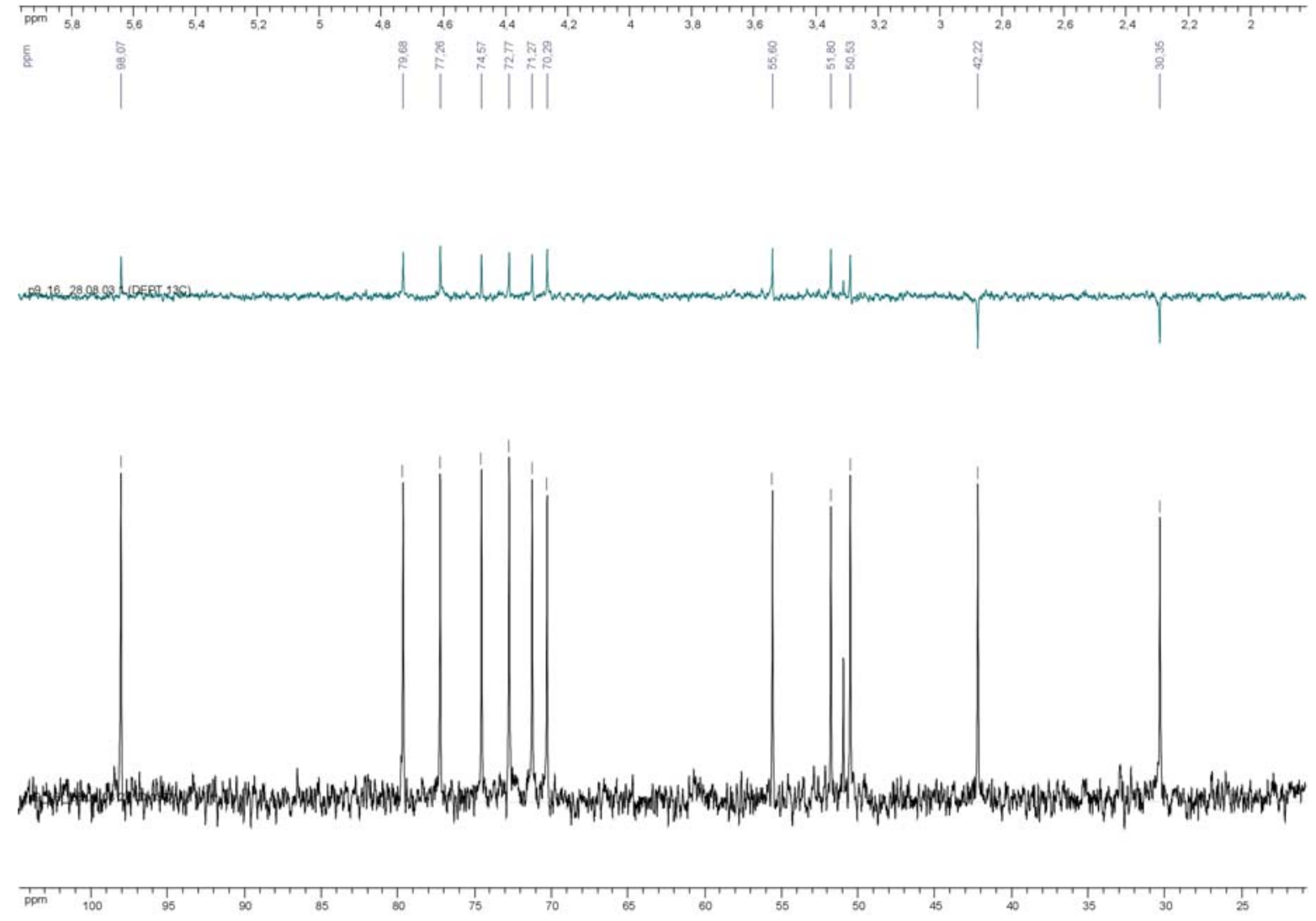

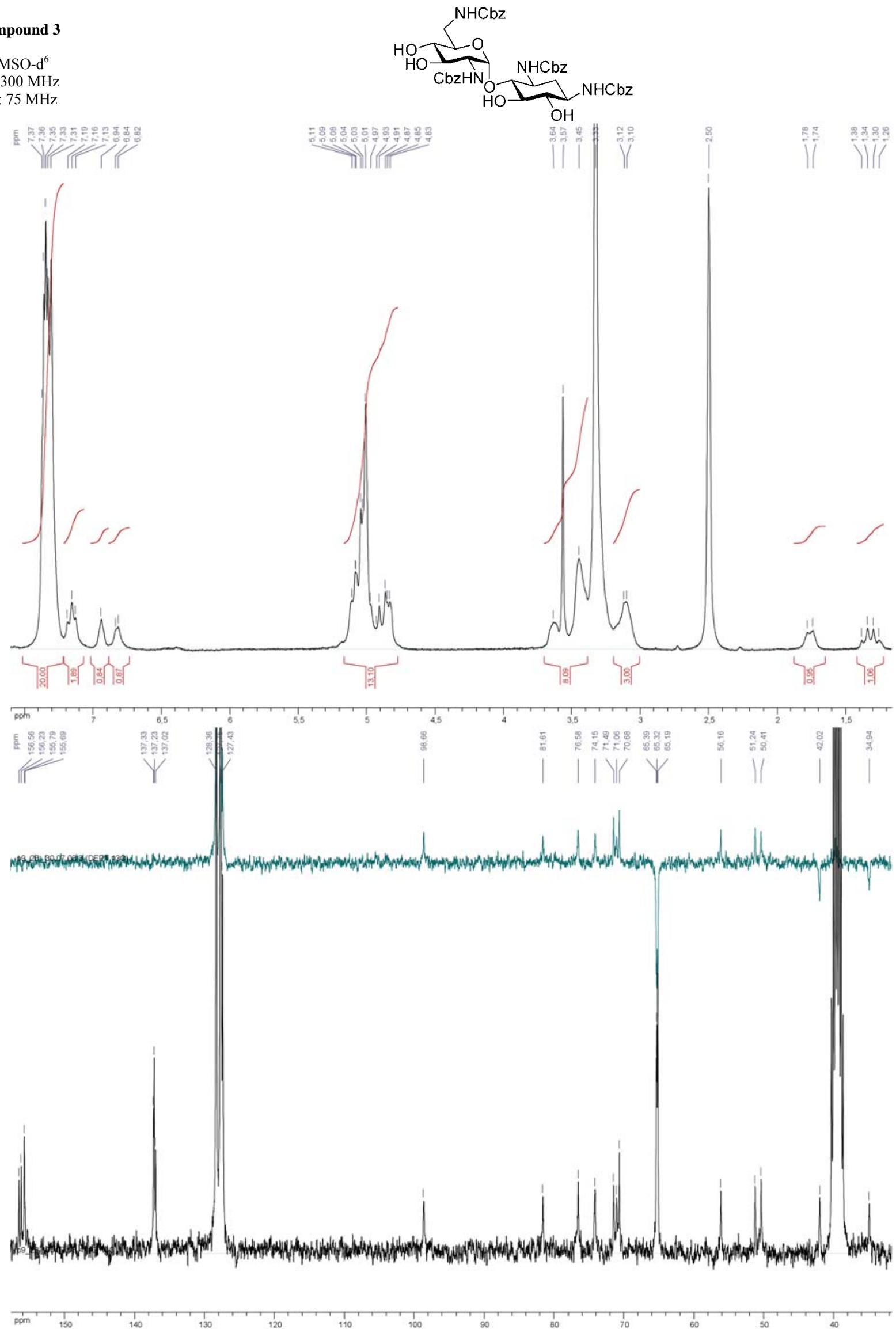
Compound 4

$\mathrm{CD}_{3} \mathrm{OD}+$

DMSO-d ${ }^{6}$

${ }^{1} \mathrm{H}: 300 \mathrm{MHz}$

${ }^{13} \mathrm{C}: 75 \mathrm{MHz}$

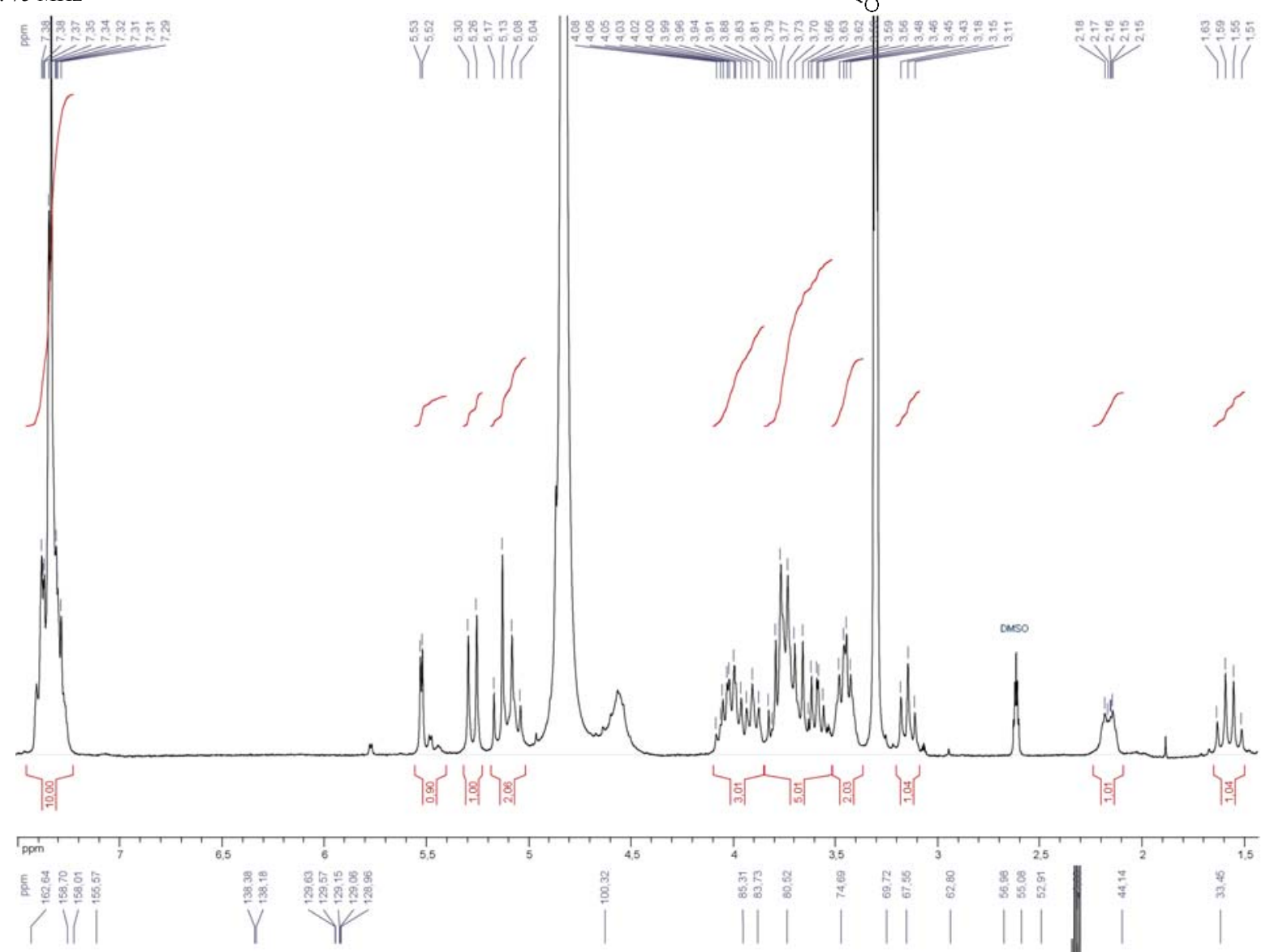

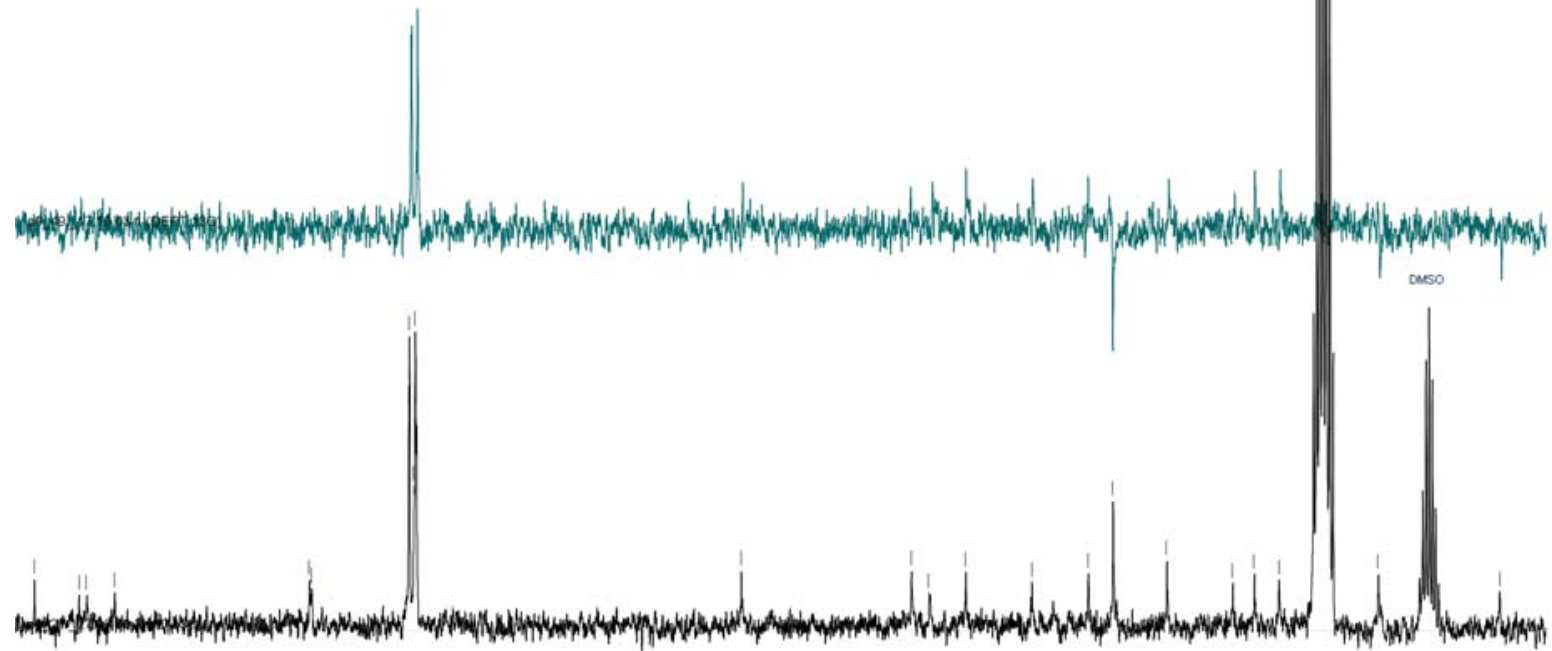

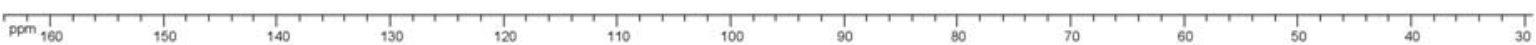


$\mathrm{CD}_{3} \mathrm{OD}$

${ }^{1} \mathrm{H}: 500 \mathrm{MHz}$

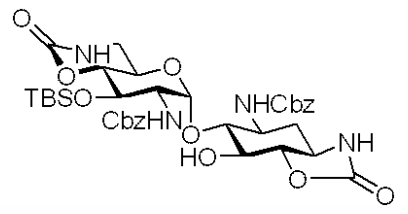

${ }^{13} \mathrm{C}: 125 \mathrm{MHz}$
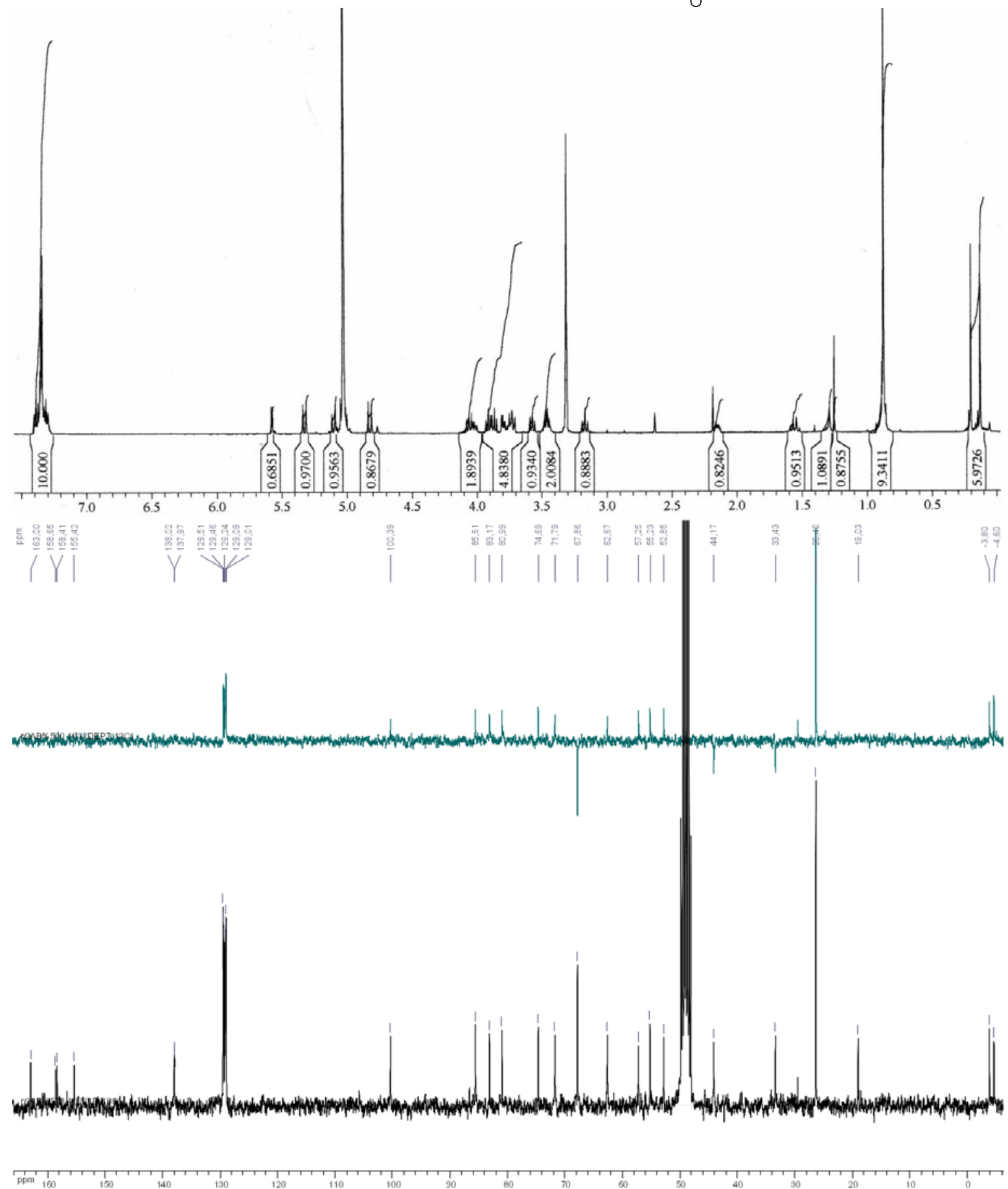

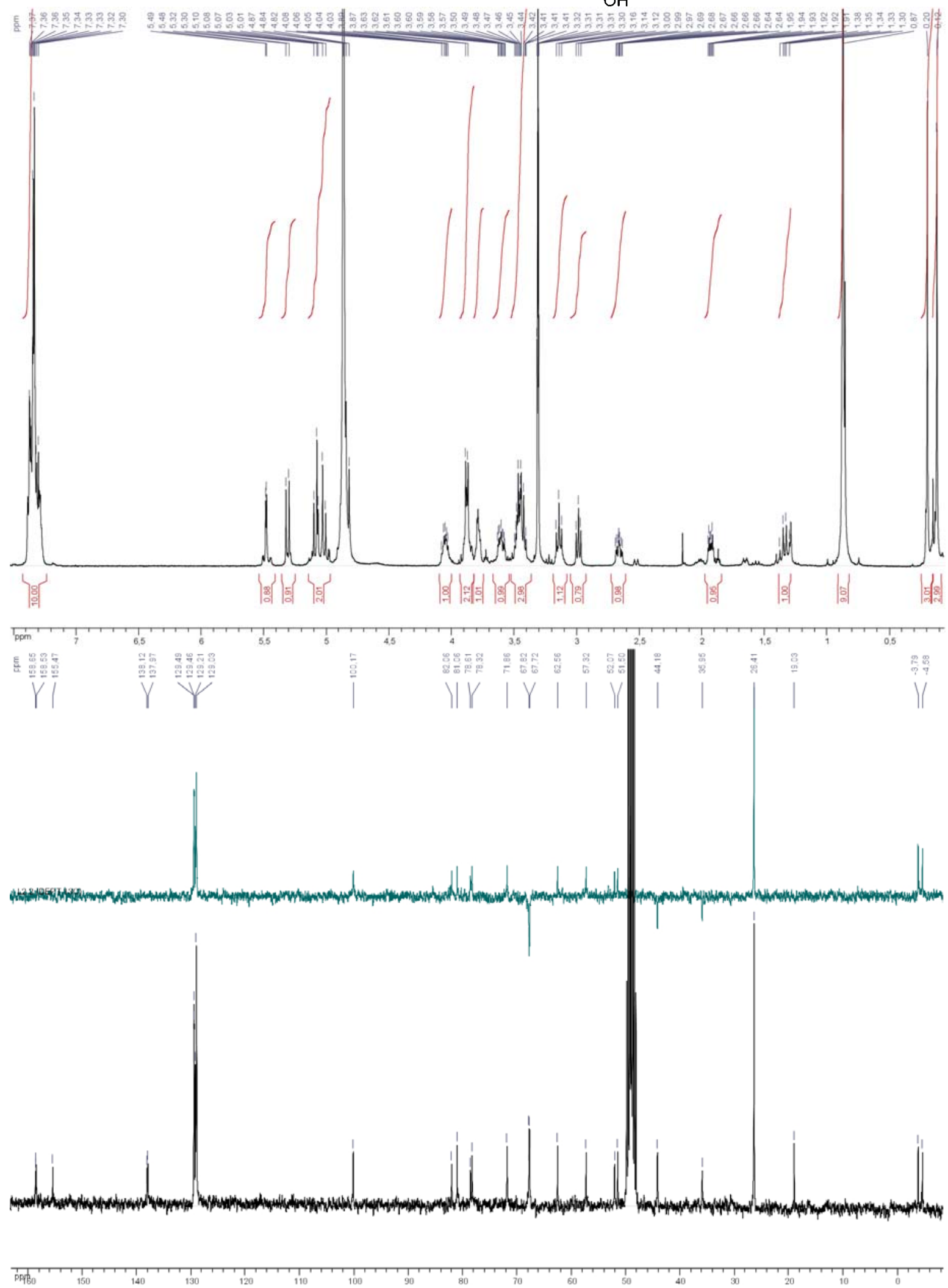
${ }^{13} \mathrm{C}: 75 \mathrm{MHz}$

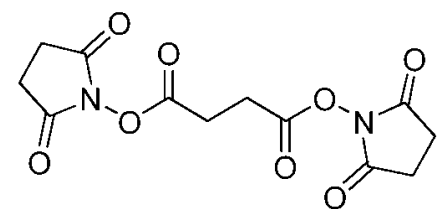

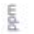
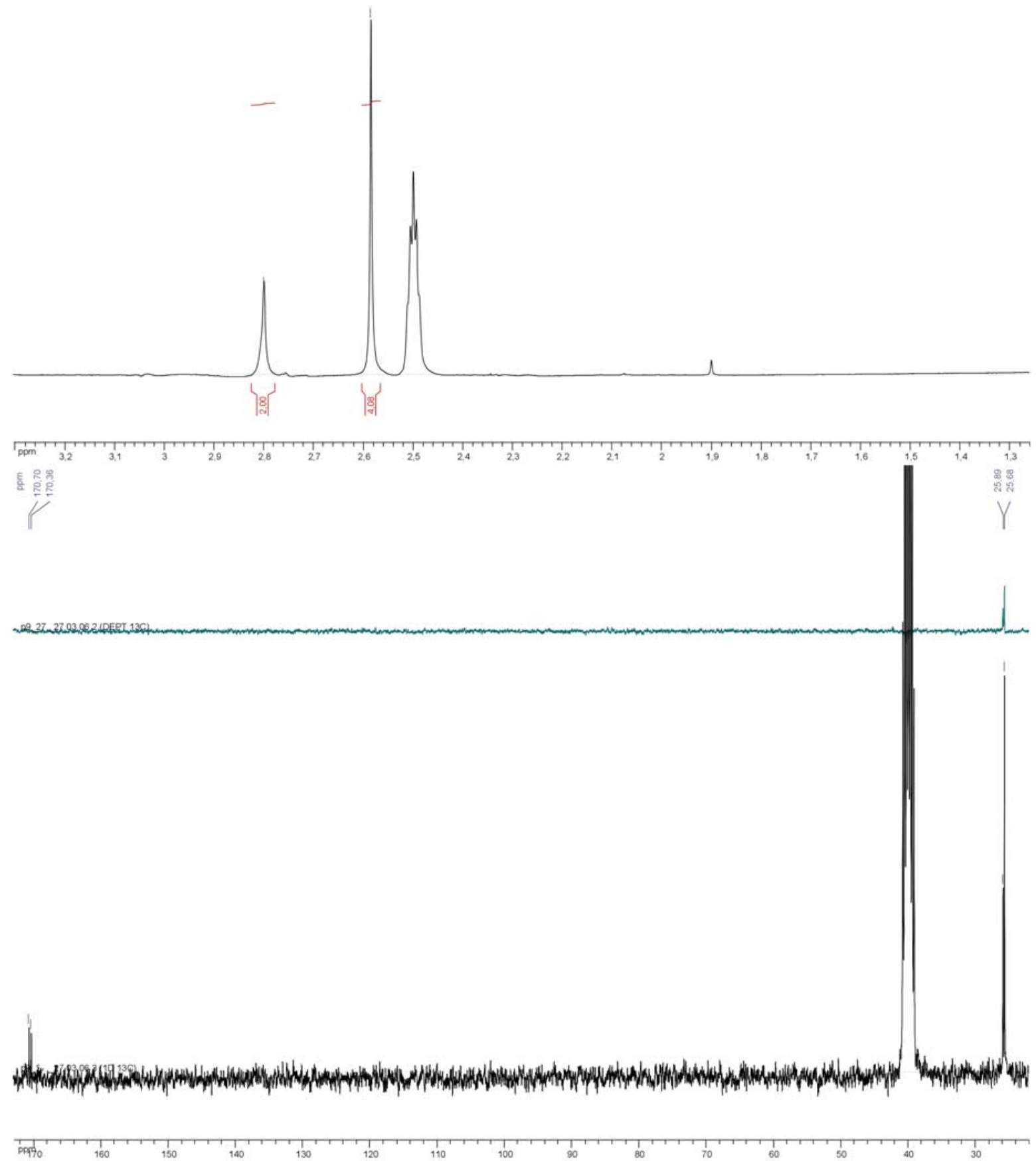
Compound 9c

DMSO-d ${ }^{6}$

${ }^{1} \mathrm{H}: 300 \mathrm{MHz}$

${ }^{13} \mathrm{C}: 75 \mathrm{MHz}$

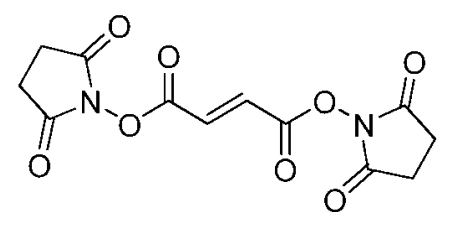

$\int$
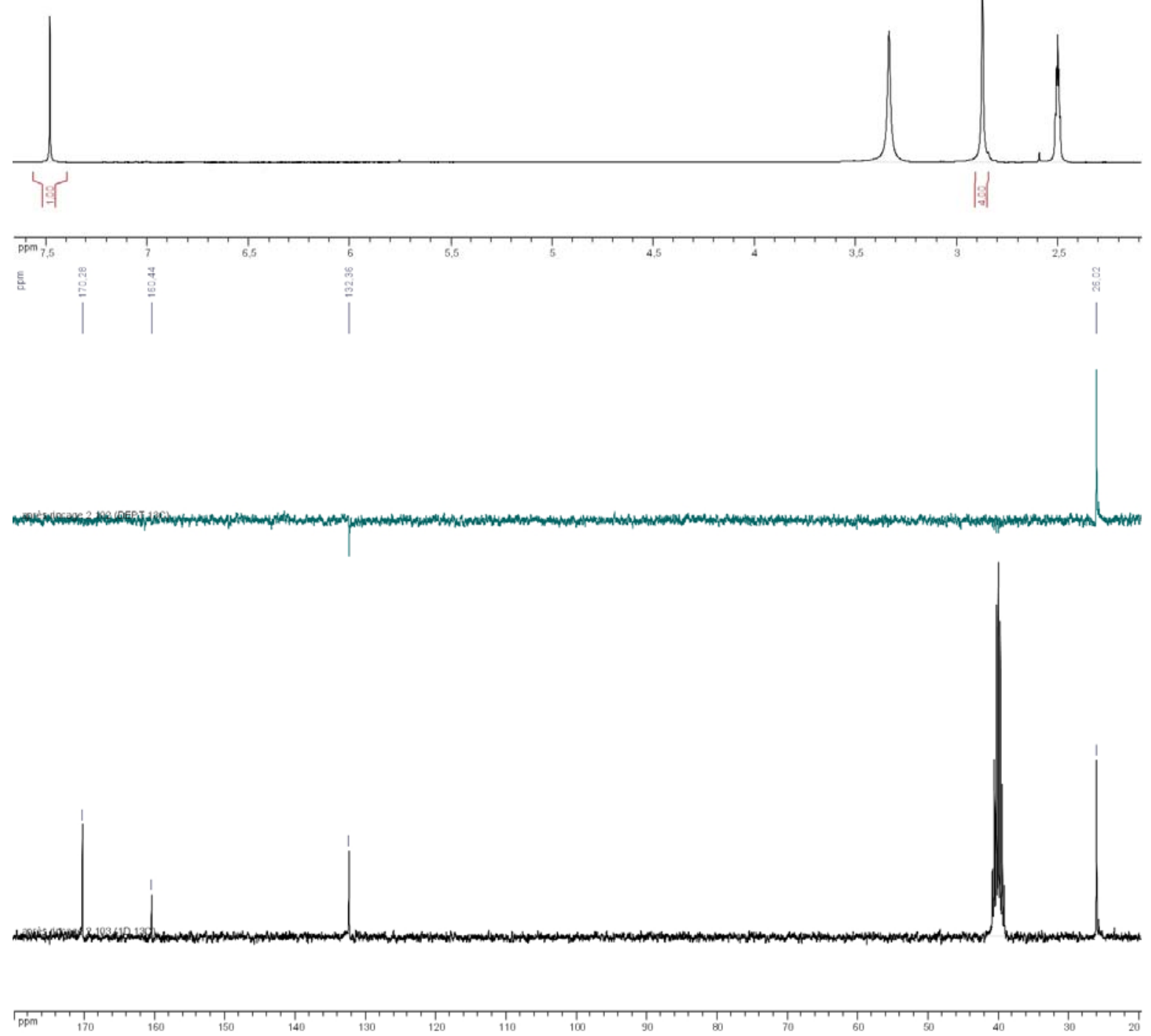

S10 
Compound 10

$\mathrm{CD}_{3} \mathrm{OD}$

${ }^{1} \mathrm{H}: 300 \mathrm{MHz}$

${ }^{13} \mathrm{C}: 75 \mathrm{MHz}$
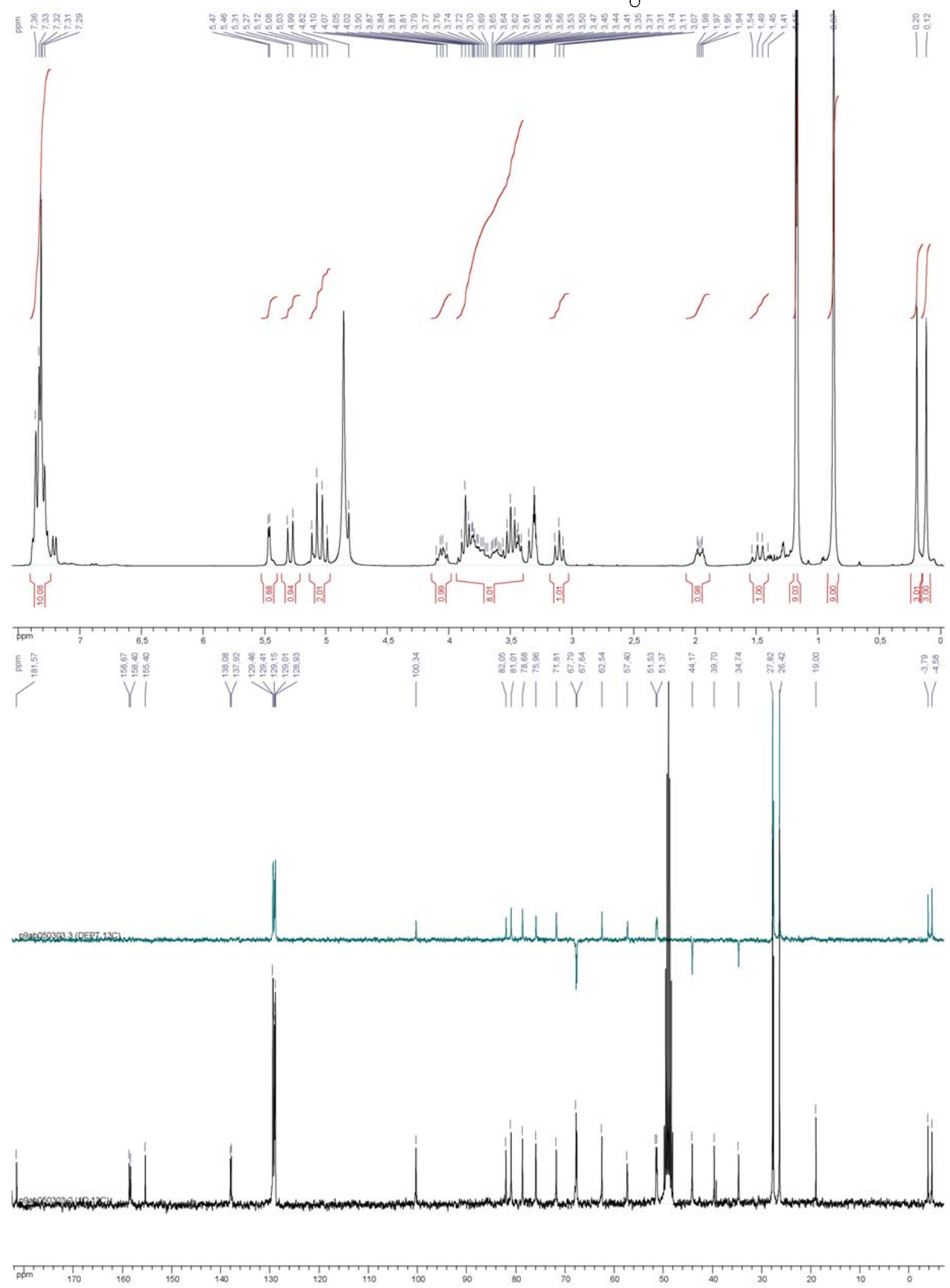
Compound 11

$\mathrm{CD}_{3} \mathrm{OD}$

${ }^{1} \mathrm{H}: 300 \mathrm{MHz}$

${ }^{13} \mathrm{C}: 75 \mathrm{MHz}$
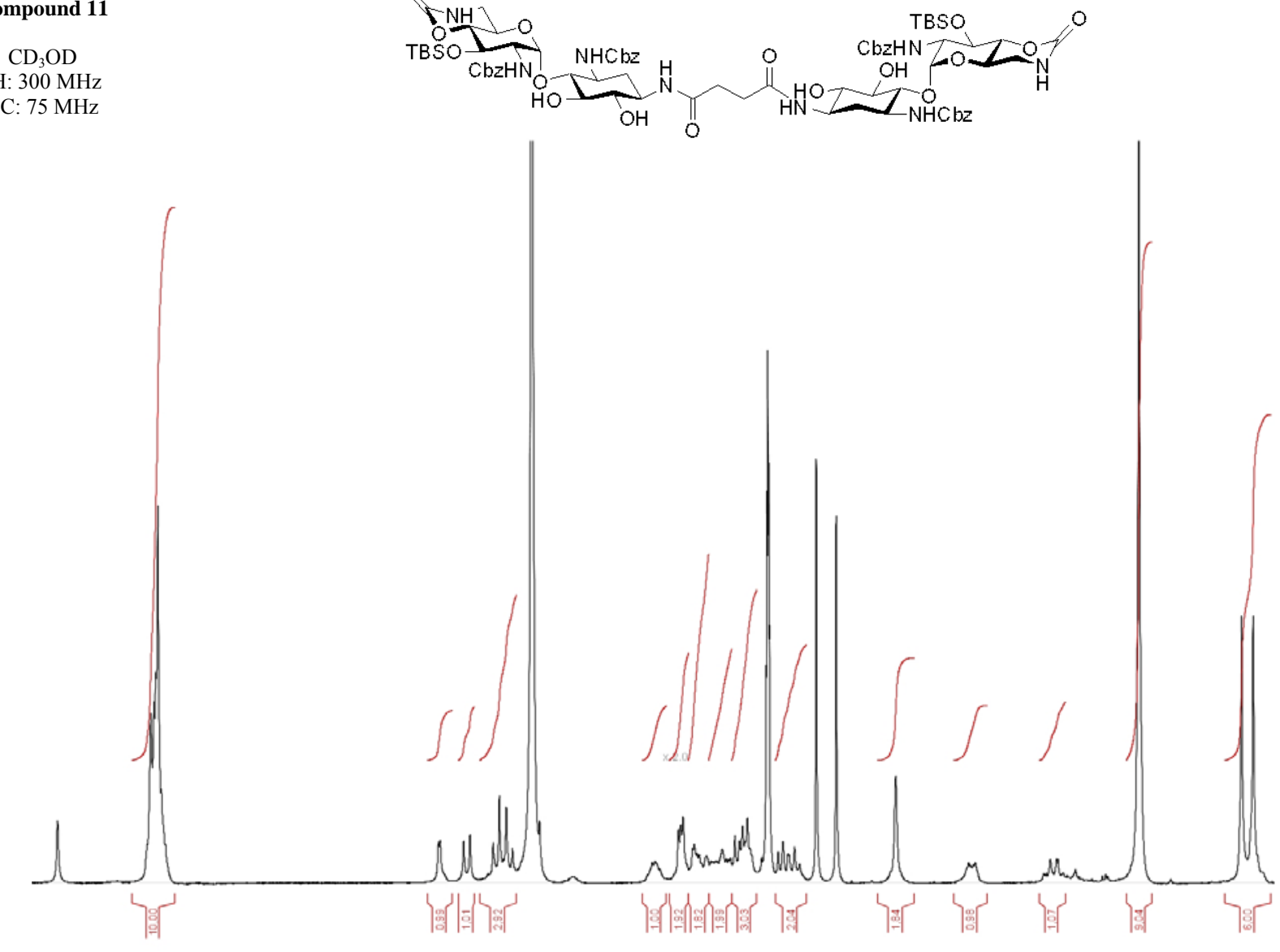
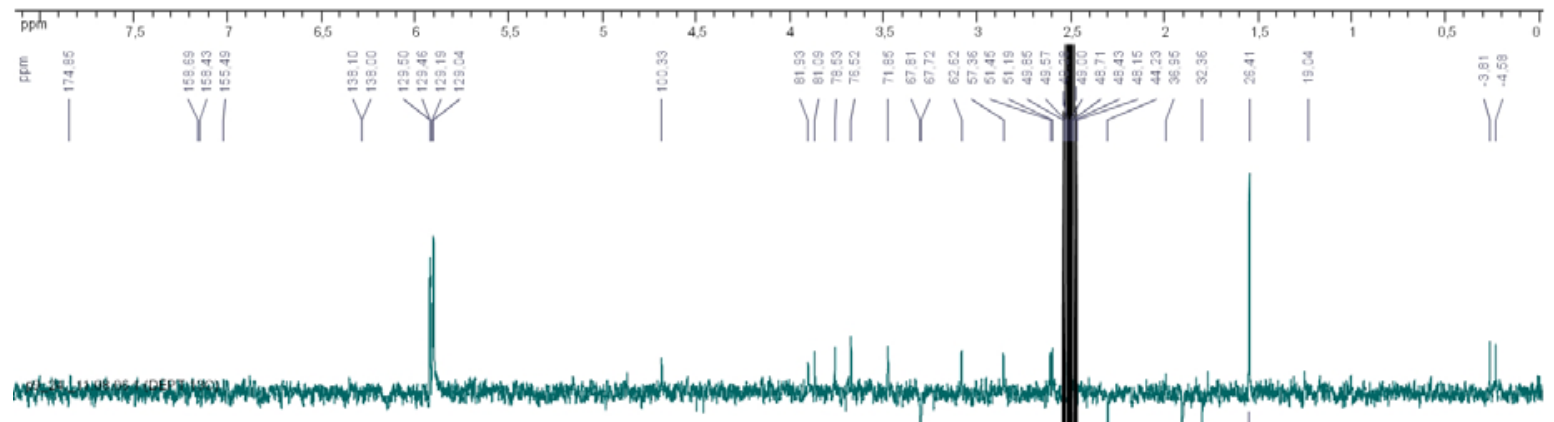

$O$

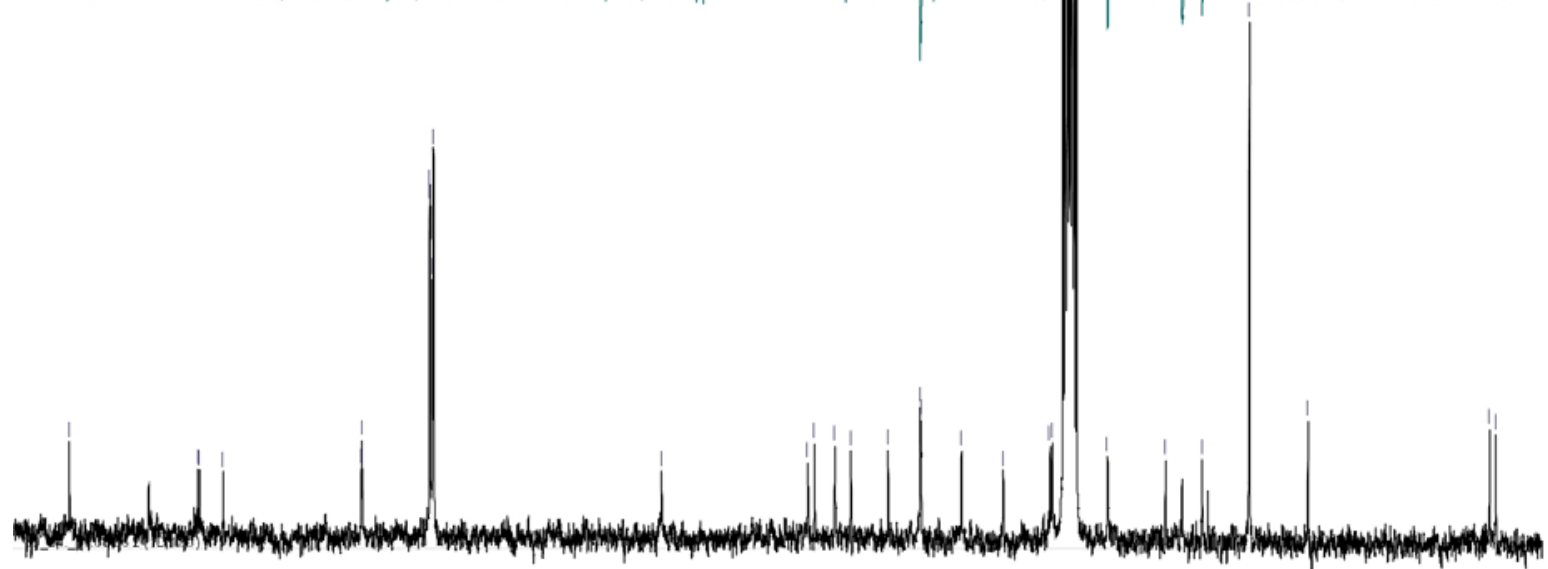

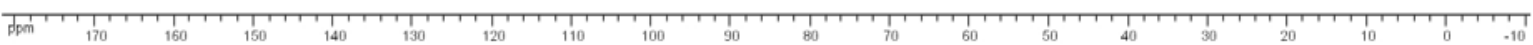


Compound 12

pyridine- $\mathrm{d}^{5}$

${ }^{1} \mathrm{H}: 500 \mathrm{MHz}$

${ }^{13} \mathrm{C}: 125 \mathrm{MHz}$

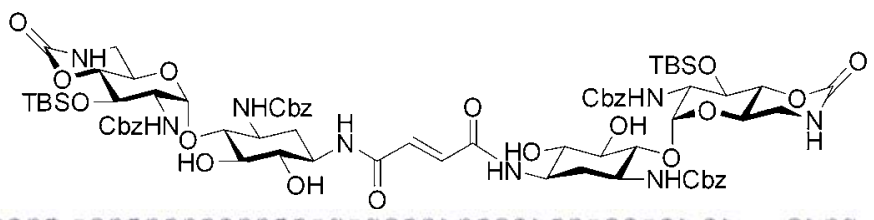

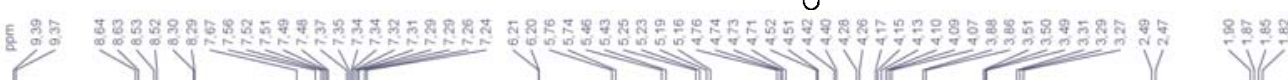
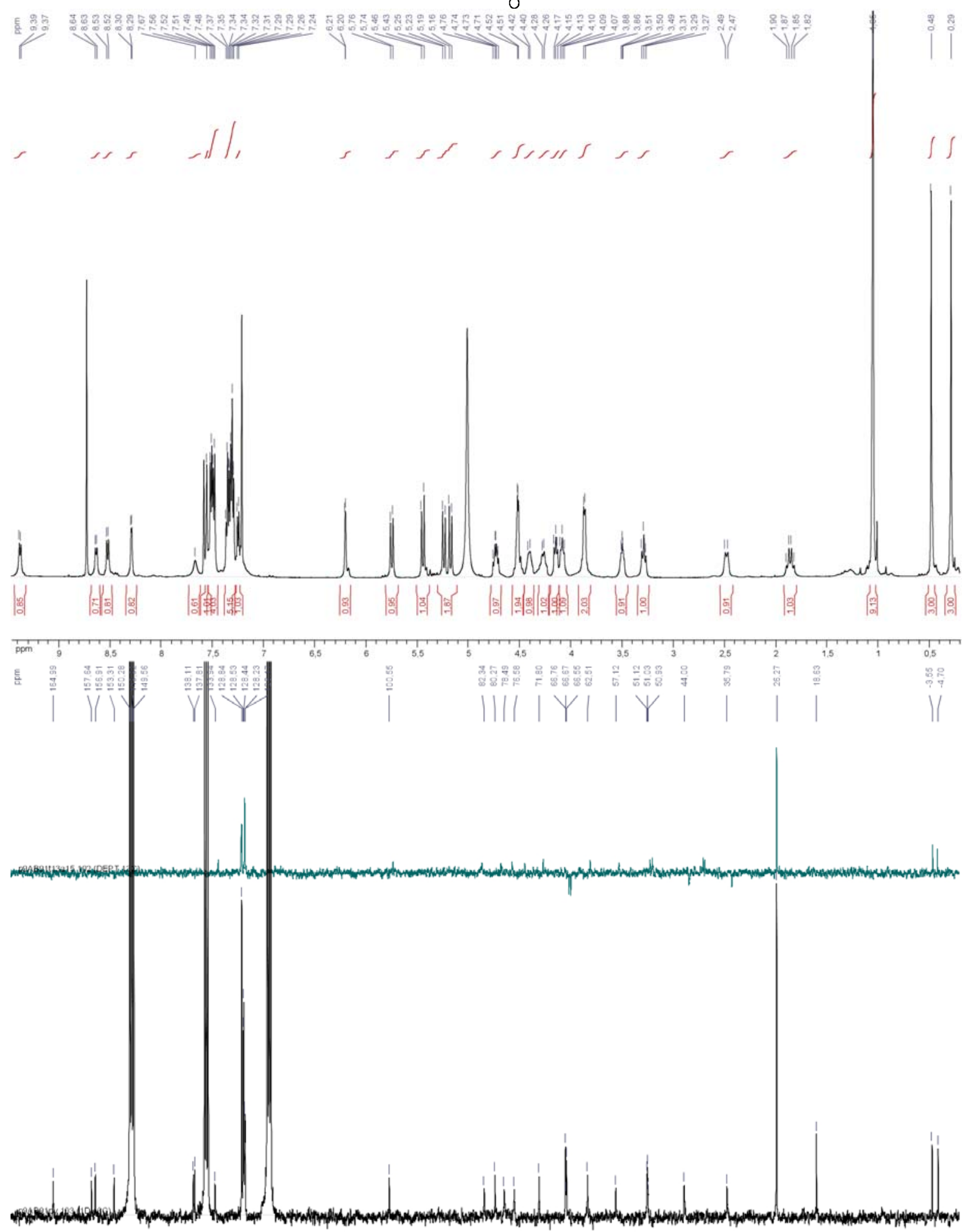

pptn

1401130 

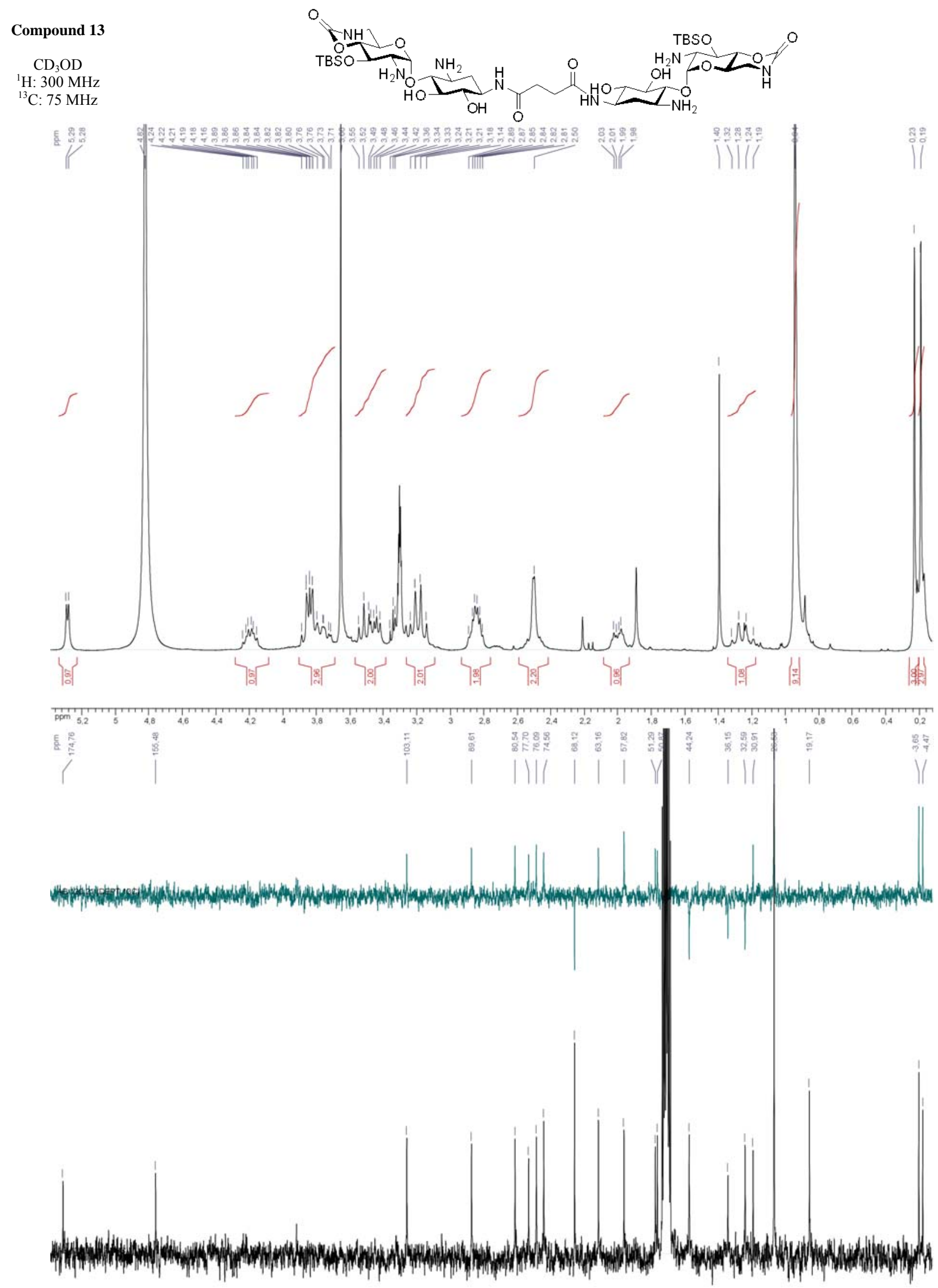

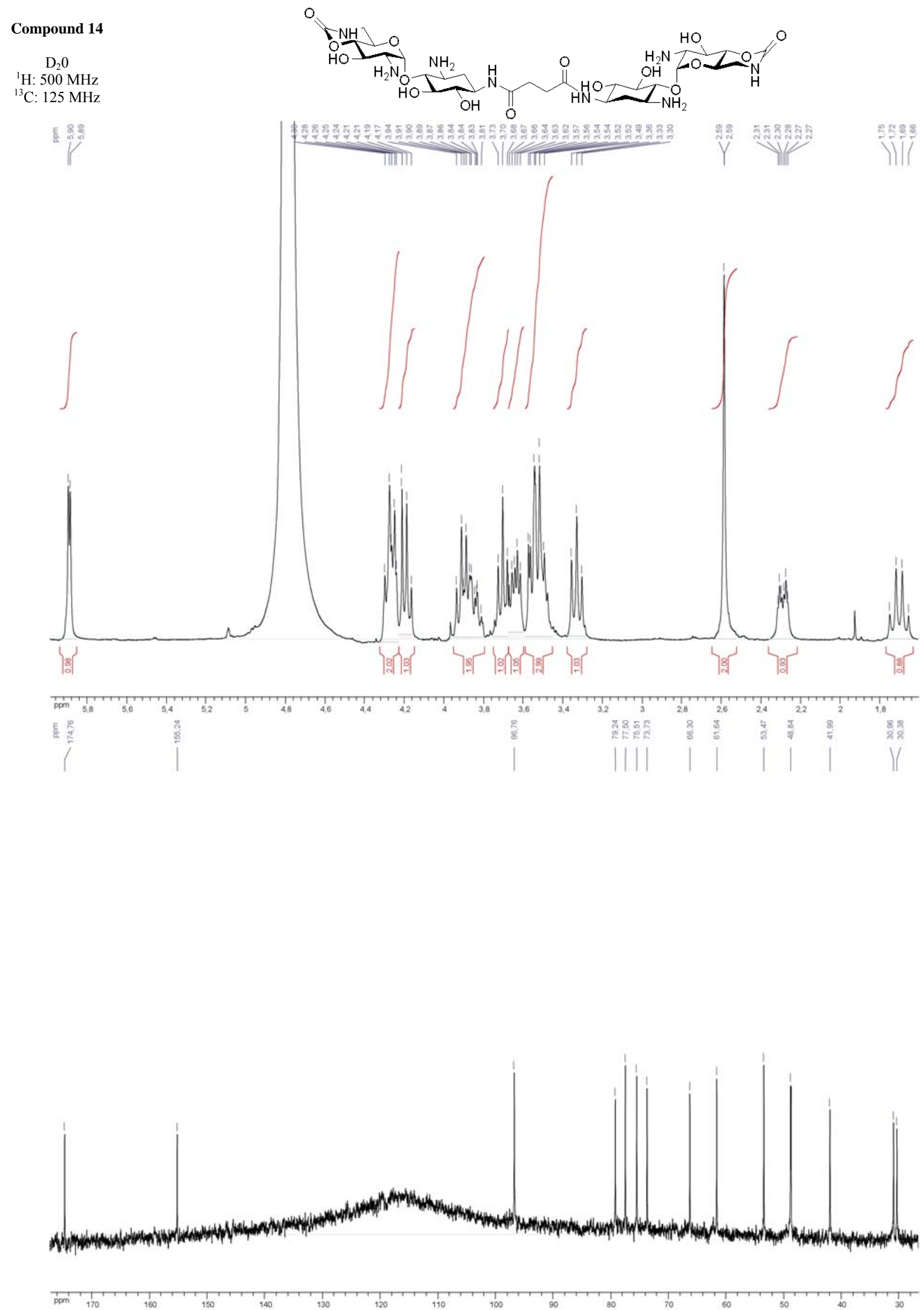
Compound 15

$\mathrm{D}_{2} \mathrm{O}$

${ }^{1} \mathrm{H}: 500 \mathrm{MHz}$

${ }^{13} \mathrm{C}: 125 \mathrm{MHz}$
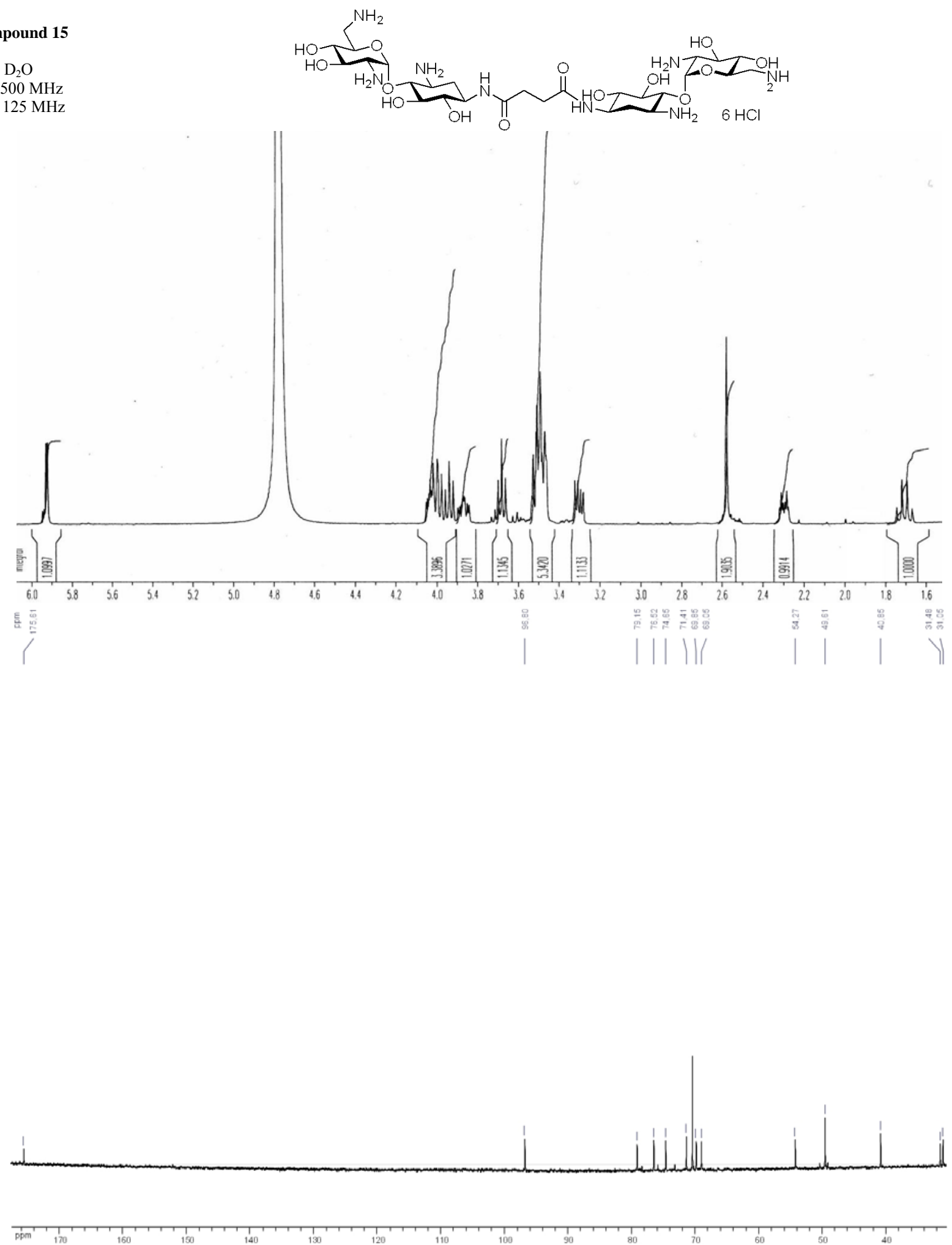
In a typical experiment, unlabeled 1-615 RNA (400 nM, 615 nucleotides long), together with a corresponding internally labeled RNA (3-5 nCi), were heated for $2 \mathrm{~min}$ at $90{ }^{\circ} \mathrm{C}$, chilled for $2 \mathrm{~min}$ on ice, and dimerization was initiated by addition of $2 \mu \mathrm{L}$ of 5-fold concentrated dimerization buffer (final concentration: $50 \mathrm{mM}$ sodium cacodylate, $\mathrm{pH} 7.5,300 \mathrm{mM} \mathrm{KCl,} 5 \mathrm{mM}$ $\mathrm{MgCl}_{2}$ ). After incubation at $37^{\circ} \mathrm{C}$ for $20 \mathrm{~min}, 100 \mu \mathrm{M}$ of aminoglycosides were added to the RNA mixture and samples were further incubated for $15 \mathrm{~min}$. Then, RNA 1-311 (2 $\mu \mathrm{M}, 311$ nucleotides long) was added as a competitor and samples were collected at $2,5,10,15,20,30$, and 60 min and analyzed on $0.8 \%$ agarose gels $\left(45 \mathrm{mM}\right.$ Tris borate $\left.\mathrm{pH} 8.3,01 \mathrm{mM} \mathrm{MgCl}_{2}\right)$ at $4{ }^{\circ} \mathrm{C}$. Gels were fixed in TCA 10\%, dried, and analyzed using a BAS 2000 Bio-Imager (Fuji).

In these competition experiments, the stronger the aminoglycoside binding, the lesser homodimer to heterodimer conversion is detected. Dimer $\mathbf{1 5}$ allowed formation of less than $40 \%$ heterodimer, suggesting that dimer $\mathbf{1 5}$ was able to bind to the DIS and to reduce the dissociation of the 'kissing complex' compared to neamine. 